\title{
DISCRIMINACÃO CONDICIONAL VS EMPARELHAMENTO COM O MODELO: UMA EXPANSÃO DO PARADIGMA DE TESTEI
}

\section{CONDITIONAL DISCRIMINATION VS. MATCHING TO SAMPLE: AN EXPANSION OF THE TESTING PARADIGM²}

\author{
Murray Sidman e William Tailby
}

NORTHEASTERN UNIVERSITY, USA

\begin{abstract}
RESUMO
O desempenho de um sujeito ${ }^{3}$ no procedimento de discriminação condicional define relações condicionais entre estímulos: "Se A1, então B1; se A2, então B2". O procedimento também pode gerar emparelhamento com o modelo. Nesse caso, os estímulos serão relacionados não apenas por condicionalidade, mas por equivalência. A1 e B1 se tornarão membros de uma classe de estímulos equivalentes, e A2 e B2 de outra. Um paradigma para testar se um procedimento de discriminação condicional gera relaçôes de equivalência utiliza três conjuntos de estímulos, $\mathrm{A}, \mathrm{B}, \mathrm{e} \mathrm{C}$, três estímulos por conjunto. Os sujeitos aprendem a selecionar as comparaçóes do Conjuntos B e do Conjunto $\mathrm{C}$ condicionalmente aos modelos do Conjunto $\mathrm{A}$. Tendo sido explicitamente ensinadas seis relações entre modelos e comparaçôes, $\mathrm{A} 1 \mathrm{~B} 1, \mathrm{~A} 1 \mathrm{C} 1, \mathrm{~A} 2 \mathrm{~B} 2, \mathrm{~A} 2 \mathrm{C} 2$, A3B3 e A3C3, os sujeitos mostram-se imediatamente capazes de emparelhar os estímulos B e C; emergem seis novas relaçôes (B1C1, B2C2, B3C3, C1B1, C2B2, C3B3). As 12 relações entre estímulos, seis ensinadas e seis emergentes, definem a existência de três classes de estímulos com três membros, A1B1C1, A2B2C2, e A3B3C3. Este paradigma foi expandido ao introduzir mais três estímulos (Conjunto $\mathrm{D}$ ), e ensinar às oito crianças não somente as relaçôes $\mathrm{AB}$ e $\mathrm{AC}$ mas também relações $\mathrm{DC}$ - selecionar comparações do Conjunto C condicionalmente aos modelos do Conjunto D. Seis crianças mostraramse imediatamente capazes de emparelhar os estímulos B e D. Ao selecionar comparações apropriadas do Conjunto $\mathrm{B}$ condicionalmente aos modelos do Conjunto D, e comparaçóes do Conjunto D condicionalmente aos modelos do Conjunto B, elas demonstraram a existência de três classes de estímulos com quatro membros, A1B1C1D1, $\mathrm{A} 2 \mathrm{~B} 2 \mathrm{C} 2 \mathrm{D} 2$, e A3B3C3D3. Essas classes mais amplas foram formadas a partir do sucesso dos sujeitos com os prérequisitos de relações condicionais de nível mais baixo; eles também foram capazes de selecionar comparações do Conjunto D condicionalmente aos modelos dos Conjuntos A e C, e fazer os emparelhamentos BC e CB que definiam a classe original com três membros. Portanto, a adição de três relações DC gerou mais 12, três em cada uma das relações $\mathrm{BD}, \mathrm{DB}, \mathrm{AD}$, e CD. A ampliação de cada classe por um novo membro resultou em um aumento desproporcional no número de relações emergentes. Testes complementares de nomeação sugeriram que a utilização, por parte do sujeito, de um mesmo nome para cada estímulo não era necessária nem suficiente para estabelecer classes de estímulos equivalentes.
\end{abstract}

Palavras-chave: discriminação condicional, emparelhamento com o modelo, equivalência de estímulos, classes de estímulos, controle de estímulos, pressionar a chave, criança

\footnotetext{
ABSTRACT

A subject's performance under a conditional-discrimination procedure defines conditional relations between stimuli: "If A1, then B1; if A2, then B2." The procedure may also generate matching to sample. If so, the stimuli will be related not only by conditionality, but by equivalence: $\mathrm{A} 1$ and $\mathrm{B} 1$ will become equivalent members of one stimulus class, A2 and B2 of another. One paradigm for testing whether a conditional-discrimination procedure has generated equivalence relations uses three sets of stimuli, A, B, and C, three stimuli per set. Subjects learn to select Set-B and Set-C comparisons conditionally upon Set-A samples. Having been explicitly taught six samplecomparison relations, $\mathrm{A} 1 \mathrm{~B} 1, \mathrm{~A} 1 \mathrm{C} 1, \mathrm{~A} 2 \mathrm{~B} 2, \mathrm{~A} 2 \mathrm{C} 2, \mathrm{~A} 3 \mathrm{~B} 3$, and $\mathrm{A} 3 \mathrm{C} 3$, subjects prove immediately capable of

1 Artigo originalmente publicado em 1982 no Journal of the Experimental Analysis of Behavior, 37, 5-22, que autorizou a publicação da tradução (Copyright 1982 by the Society for the Experimental Analysis of Behavior, Inc.). Tradução realizada por Lauro E. G. Nalini (Universidade Católica de Goiás) e Raquel Maria de Melo (Uiversidade de Brasília).

2 Essa pesquisa foi financiada pelos auxílios MH30063, HD05124 e NE-G-00-3-0011. Agradecemos a F. Garth Fletcher pelo desenho, construção e manutenção do equipamento.

3 O termo sujeito tem sido atualmente substituído por expressões consideradas mais "politicamente" corretas; na época da publicação original do artigo o termo era amplamente empregado (nota dos tradutores)
} 
matching the B- and C-stimuli; six new relations emerge (B1C1, B2C2, B3C3, C1B1, C2B2, C3B3). The 12 stimulus relations, six taught and six emergent, define the existence of three three-member stimulus classes, $\mathrm{A} 1 \mathrm{~B} 1 \mathrm{C} 1, \mathrm{~A} 2 \mathrm{~B} 2 \mathrm{C} 2$, and $\mathrm{A} 3 \mathrm{~B} 3 \mathrm{C} 3$. This paradigm was expanded by introducing three more stimuli (Set $\mathrm{D})$, and teaching eight children not only the $\mathrm{AB}$ and $\mathrm{AC}$ relations but $\mathrm{DC}$ relations also - selecting Set- $\mathrm{C}$ comparisons conditionally upon Set-D samples. Six of the children proved immediately capable of matching the B-and D stimuli to each other. By selecting appropriate Set-B comparisons conditionally upon Set-D samples, and Set-D comparisons conditionally upon Set-B samples, they demonstrated the existence of three four-member stimulus classes, A1B1C1D1, A2B2C2D2, and A3B3C3D3. These larger classes were confirmed by the subjects' success with the prerequisite lower-level conditional rela-tions; they were also able to select Set-D comparisons conditionally upon samples from Sets $\mathrm{A}$ and $\mathrm{C}$, and to do the $\mathrm{BC}$ and $\mathrm{CB}$ matching that defined the original three-member classes. Adding the three $\mathrm{DC}$ relations therefore generated 12 more, three each in $\mathrm{BD}, \mathrm{DB}, \mathrm{AD}$, and $\mathrm{CD}$. Enlarging each class by one member brought about a disproportionate increase in the number of emergent relations. Ancillary oral naming tests suggested that the subject's application of the same name to each stimulus was neither necessary nor sufficient to establish classes of equivalent stimuli.

Key words: conditional discrimination, matching to sample, stimulus equivalence, stimulus classes, stimulus control, key press, children

Dados dois estímulos discriminativos, B1 e B2, um sujeito seleciona B1 se o estímulo condicional A1 está presente, e seleciona B2 se o estímulo condicional é A2. Esta discriminação condicional fornece uma definição de relaçôes condicionais entre estímulos em termos de procedimento. Em sua forma mais simples, as relaçôes condicionais são: Se A1, então B1; se A2, então B2. Embora considerações adicionais possam levar a uma descrição mais precisa de uma relação "se..., então...", sua existência é diretamente observável a partir das interações correntes do sujeito com o procedimento. A realização de testes para verificar a existência de uma relação condicional não requerer modificação no procedimento estabelecedor.

Assume-se freqüentemente que uma discriminação condicional bem estabelecida demonstra não apenas relações condicionais entre os estímulos, mas também relações de equivalência. Adicionalmente à relação "se..., então...", supõe-se também que os estímulos A1 e B1 são equivalentes; similarmente, supõe-se que os estímulos A2 e B2 estão relacionados tanto por condicionalidade quanto por equivalência. Pesquisadores que admitem, explícita ou implicitamente, que o procedimento de discriminação condicional gera relações de equivalência chamam, freqüentemente, o desempenho do sujeito de "emparelhamento com o modelo". Os estímulos B1 e B2 tornam-se estímulos de comparação, para serem comparados aos estímulos modelo A1 e A2 e emparelhados apropriadamente. Quando todos os estímulos modelo e de comparação são fisicamente diferentes, a equivalência é sugerida denominando-se o desempenho de emparelhamento de "não-identidade", emparelhamento "arbitrário", ou igualação "simbólica".

Diferentemente de condicionalidade, equivalência não é definível apenas por referência às interações do sujeito com o procedimento estabelecedor. Para determinar se o desempenho envolve algo mais do que relaçôes condicionais entre estímulos modelo e de comparação, são necessários testes adicionais. Suponha, por exemplo, uma relação, $R$, entre os estímulos a e $b$, que satisfaz as exigências de procedimento para a condicionalidade, ou "se a, então b”. A relação entre $a$ e $b$, também é uma relação de equivalência? $\mathrm{O}$ desempenho do sujeito não dá qualquer pista. Contudo, testes apropriados podem ser derivados a partir de três 
propriedades que os textos de matemática elementar moderna especificam como a definição da relação de equivalência: reflexividade, simetria e transitividade.

Para determinar se a relação condicional, $R$, é reflexiva, deve-se demonstrar que cada estímulo mantém relação com ele mesmo; $a R a$ (se $a$, então $a$ ) e $b R b$ (se $b$, então $b$ ) devem ser verdadeiras. Portanto, a propriedade de reflexividade pode ser testada por um procedimento de emparelhamento por identidade que requer que o sujeito emparelhe o estímulo $a$ com ele mesmo, e o estímulo $b$ com ele mesmo.

Não será suficiente ensinar as relações condicionais, $a R a$ e $b R b$. Não se sabe se um sujeito a quem as relações foram ensinadas está emparelhando cada estímulo a ele mesmo (se emparelhamento está realmente ocorrendo), ou se está sendo controlado talvez por uma característica do modelo e uma outra característica do estímulo de comparação correto. Por exemplo, ao invés de emparelhar "vermelho" com "vermelho" e "verde" com "verde", o sujeito poderia estar emparelhando "vermelho" com "claro", e "verde" com "escuro". Somente se o sujeito emparelhar cada novo estímulo com ele mesmo, sem reforçamento diferencial ou sem outras instruçôes adicionais, pode-se ter certeza de que a identidade é a base para o desempenho. Dado um sujeito que está familiarizado com os estímulos e procedimentos, a prova de reflexividade é o emparelhamento de identidade generalizado.

Para demonstrar que a relação $R$ é simétrica, deve-se mostrar que tanto $a R b$ quanto $b R a$ são verdadeiras. Um sujeito que emparelha o modelo $a$ com a comparação $b$ deve, então, sem treino adicional, emparelhar o modelo $b$ com o estímulo de comparação $a$, fa- zendo a inversão de "se $a$, então $b$ " para "se $b$, então $a$ ". Dado um sujeito que esteja familiarizado com cada um dos estímulos separadamente, como modelo e como comparação, a prova de simetria da relação $a R b$ é a reversibilidade funcional entre modelo e comparação (Sidman, Rauzin, Lazar, Cunningham, Tailby, \& Carrigan, 1982).

Para determinar se R é transitiva, é necessário um terceiro estímulo, $c$. Uma vez que as relações "se $a$, então $b$ " e "se $b$, então $c$ " tenham sido estabelecidas, a transitividade requer que a relação "se $a$, então $c$ " emerja sem reforçamento diferencial ou sem outras instruções adicionais. Dado um sujeito que tenha aprendido duas relações condicionais, $a R b$ e $b R c$, com o estímulo de comparação na primeira servindo como modelo na segunda, a prova da transitividade é a emergência de uma terceira relação condicional, $a R c$, em que o sujeito emparelha o modelo da primeira relação com o estímulo de comparação da segunda.

Denominar uma relação condicional de "emparelhamento com o modelo", então, requer a prova de que a relação possui as três propriedades de uma relação de equivalência, tal como listadas na parte superior da Tabela 1. Emparelhamento generalizado bem sucedido provará que a relação é reflexiva, uma propriedade que deve ser verdadeira para cada estímulo. A reversibilidade amostra-comparação (Lazar, 1977) provará que a relação é simétrica, uma propriedade que deve ser verdadeira para cada par de estímulos relacionados. A emergência de uma terceira relação, em que o sujeito emparelha o modelo de uma das duas relações pré-requisitos com a comparação da outra, provará a transitividade, uma propriedade que deve ser verdadeira para pelo menos três estímulos inter-relacionados. 
Tabela 1

Relações de Equivalência

As relaçôes de equivalência devem ser:

1. Reflexivas: $a R a$

2.Simétricas: Se $a R b$, então $b R a$

3. Transitivas: Se $a R b$ e $b R a$, então $a R c$

Os testes combinados de simetria e transitividade são:

A.Ensinar $a \boldsymbol{R} b$ e $a R c$. Testar $b \boldsymbol{R} c$ e $c \boldsymbol{R} b$

B.Ensinar $b R$ a e $c R a$. Testar $b R c$ e $c R b$

Simetria e transitividade podem ser avaliadas simultaneamente. $\mathrm{Na}$ preparação de um tipo de teste combinado (A, na parte inferior da Tabela 1), primeiro ensina-se ao sujeito duas relações, $a R b$ e $a R c$, que compartilham o mesmo modelo. A seguir, testa-se a emergência das relações condicionais, $b R c$ e $c R b$. Se R é simétrica, de tal forma que tanto $a R b$ quanto $b R a$ são verdadeiras, então $b R a$ e $a R c$ produzirão $b R c$ por transitividade. Similarmente, se tanto $a R c$ quanto $c R a$ mostram-se verdadeiras por simetria, a combinação de $c R a$ e $a R b$-produzirá $c R b$, por transitividade. A emergência de relações condicionais novas, $b R c$ e $c R b$, requer que as relações estabelecidas explicitamente, $a R b$ e $a R c$, sejam simétricas e transitivas.

Nos primeiros experimentos que usaram estes testes para determinar se procedimentos de discriminação condicional geram desempenhos de emparelhamento com o modelo (Sidman, 1971; Sidman \& Cresson, 1973), jovens retardados inicialmente mostraram ser capazes de emparelhamento de identidade generalizado, alcançando assim o critério de reflexividade. Eles, então, aprenderam a (ou demonstraram que já eram capazes de) selecionar figuras (estímulos de comparação) condicionalmente a qualquer um dentre 20 nomes de figuras ditados (estímulos modelo); a seta contínua $A B$ na Figura 1 representa 20 relações

condicionais (A1B1, A2B2, ... A20B20). Para determinar se as relações $A B$ incluíam equivalência, adicionalmente à condicionalidade, foi necessário utilizar um outro conjunto de discriminaçôes condicionais. Os sujeitos aprenderam a selecionar nomes impressos condicionalmente aos mesmos 20 nomes ditados; a seta contínua AC na Figura 1 representa as 20 novas relaçōes (AlCl, $\mathrm{A} 2 \mathrm{C} 2, \ldots \mathrm{A} 20 \mathrm{C} 20)$. Após completar os treinos $\mathrm{AB}$ e $\mathrm{AC}$, os sujeitos podiam selecionar qualquer uma das 20 figuras ou qualquer um dos 20 nomes de figuras impressos condicionalmente ao nome ditado.

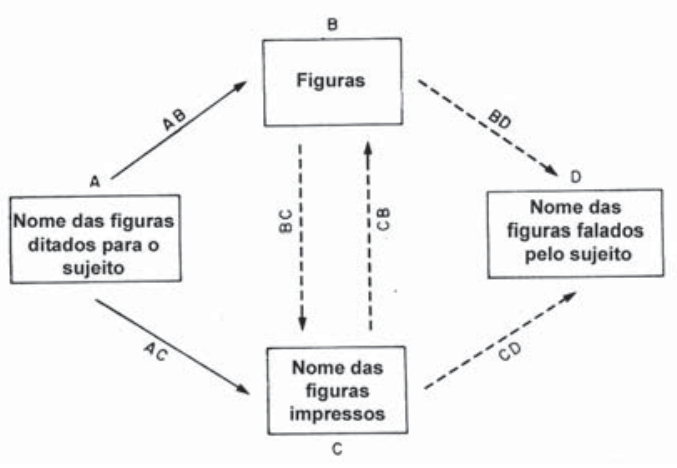

Figura 1 - O paradigma básico de equivalência. Os retângulos A, B, e C representam estímulos, e o retângulo $\mathrm{D}$ representa as respostas de nomeação oral. As setas AB, AC, BC e CB apontam dos estímulos modelos para os estímulos de comparação e representam conjuntos de relaçóes condicionais. As setas $\mathrm{BD}$ e CD apontam dos estímulos para as respostas de nomeação. As setas contínuas representam relações condicionais que são explicitamente ensinadas aos sujeitos. As setas tracejadas representam relaçôes condicionais ou relações de nomeação oral que emergem após outras terem sido explicitamente ensinadas.

Foi possível, então, verificar se as relações $\mathrm{AB}$ e $\mathrm{AC}$ eram relaçōes de equivalência aplicando o teste combinado de simetria e transitividade (A, na Tabela 1). A demonstração da equivalência exigiu que os sujeitos selecionassem uma palavra impressa apropriada condicionalmente a uma figura modelo (BC), e selecionassem uma figura apropriada condicionalmente a uma palavra impressa (CB). Os sujeitos com retardo relacionaram sim as figuras e nomes impressos 
corretamente, embora não tenham sido treinados explicitamente a fazê-lo, e tenham demonstrado nos pré-testes que eram incapazes de assim fazê-lo antes de aprenderem as discriminaçôes condicionais AB e AC. Portanto, as relações condicionais alcançaram os critérios de reflexividade, simetria e transitividade, e os desempenhos puderam ser denominados de "emparelhamento com o modelo".

A habilidade emergente dos sujeitos em realizar dois novos conjuntos de tarefas de emparelhamento, $\mathrm{BC}$ e CB, confirmou a criação de 20 classes de estímulos equivalentes com três membros: A1B1C1, A2B2C2, ... A20B20C20. Uma das classes, por exemplo, continha a palavra ditada "menino" (“boy”), figuras de meninos, e a palavra impressa menino (boy); uma outra continha a palavra ditada "carro" ("car"), figuras de carros, e a palavra impressa carro (car). Uma conseqüência necessária do estabelecimento de classes de estímulos equivalentes foi a habilidade dos sujeitos de emparelhar os membros de uma classe entre si mesmo sem nunca terem feito isto antes. O próprio processo de teste pode, portanto, gerar a emergência de novos desempenhos de emparelhamento com o modelo sem que eles tenham sido explicitamente ensinados. A formação de classes de estímulos permite economia e eficiência impressionantes no ensino e na aprendizagem. $\mathrm{O}$ treino direto de 40 relações condicionais (20 AB e $20 \mathrm{AC}$ ) gerou a emergência de mais 40 (20 BC e $20 \mathrm{CB})$. De fato, o subproduto foi consideravelmente maior; os sujeitos também tornaram-se capazes de nomear em voz alta as figuras (BD) e as palavras impressas (CD). Embora o emparelhamento com o modelo não exigisse que os sujeitos nomeassem os estímulos, o que eles habitualmente não faziam, a nomeação oral emergiu quando testada. $\mathrm{O}$ treino original de 40 relações condicionais criou 40 relações condicionais novas e 40 relações de nomeação - 80 desempenhos novos.

Um dos principais objetivos do presente experimento foi adicionar mais um estímulo a cada classe e assim testar o poder das relaçôes de equivalência em gerar uma rede mais extensa de estímulos intercambiáveis. A Figura 2 mostra os estímulos e ilustra a base lógica do experimento. Estudos prévios usando símbolos da língua inglesa necessitaram de pré-testes extensivos para assegurar que os sujeitos não podiam inicialmente realizar o emparelhamento crítico e a nomeação. Com o intuito de eliminar tanto o tempo requerido pelos pré-testes quanto os problemas gerados pela exposição a tarefas que as crianças não são capazes de desempenhar, e para evitar o dile-

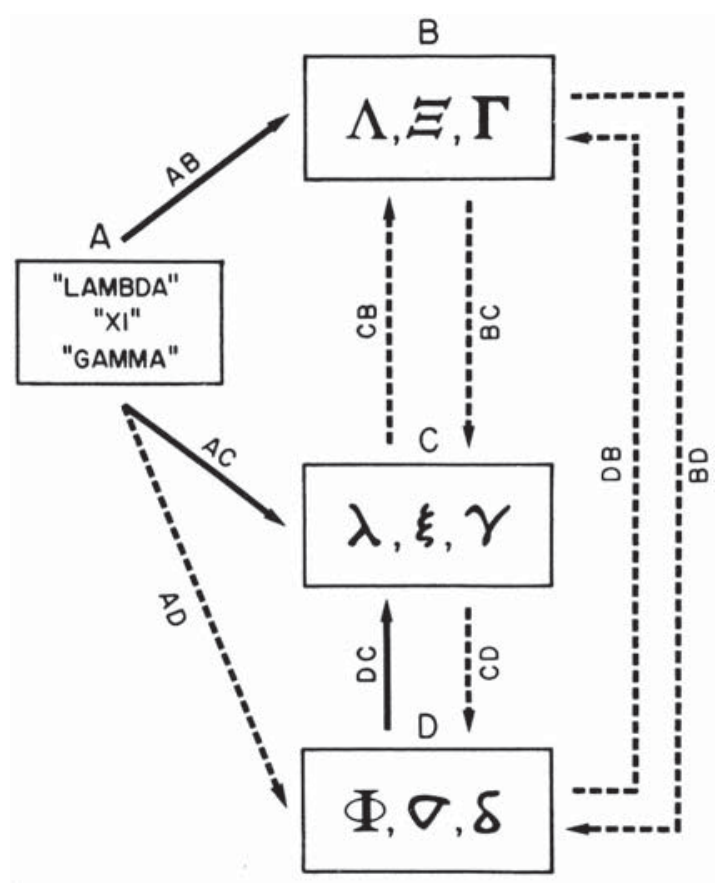

Figura 2-O paradigma de equivalência no presente experimento. Os estímulos são um conjunto de nomes ditados de letras Gregas (Conjunto A) e três conjuntos de letras Gregas impressas (Conjuntos B,C e D), três letras em cada conjunto. As setas apontam dos estímulos modelos (apenas um apresentado de cada vez) para os estímulos de comparação. As setas contínuas $\mathrm{AB}, \mathrm{AC}$ e $\mathrm{DC}$ representam relaçôes condicionais que são explicitamente ensinadas aos sujeitos. As setas tracejadas $\mathrm{CB}, \mathrm{BC}, \mathrm{AD}, \mathrm{CD}, \mathrm{BD}$, e DB representam relaçôes condicionais que são testadas após as outras relaçôes terem sido explicitamente ensinadas. 
ma metodológico de reforçar ou não respostas corretas durante os pré-testes, este experimento utilizou letras gregas e os nomes das letras, estímulos que se poderia supor que não eram familiares aos sujeitos e, portanto, não exigindo prétestes. Simplificação adicional foi obtida reduzindo o número de estímulos de 20 para três em cada conjunto.

$\mathrm{Na}$ Figura 2, o 'triângulo" superior ABC representa uma replicação simplificada dos experimentos sumarizados no triângulo da esquerda na Figura 1. Os sujeitos aprenderam a selecionar as letras dos Conjuntos $\mathrm{B}$ e $\mathrm{C}$ condicionalmente aos nomes ditados (A). Se as relações condicionais, $\mathrm{AB}$ e $\mathrm{AC}$, forem também relações de equivalência, o Teste $A$ (Tabela 1 ) revelará a habilidade dos sujeitos em emparelhar as letras dos Conjuntos B e C umas com as outras (BC e $\mathrm{CB})$. Três classes de estímulo com três membros devem emergir, cada uma contendo o nome da letra ditado, uma letra do Conjunto B e uma letra do Conjunto C.

Os sujeitos serão ensinados também a selecionar letras de comparação do Conjunto $\mathrm{C}$ condicionalmente a modelos do conjunto D. As novas relações DC podem expandir as classes $\mathrm{ABC}$ ? Se elas o fizerem, cada classe de três membros ganhará um quarto membro do Conjunto D: o phi maiúsculo juntar-se-á à classe "lambda"; o sigma minúsculo à classe "xi"; e o delta minúsculo à classe "gamma”. Os sujeitos seriam capazes de emparelhar cada estímulo com outro qualquer da sua classe. Tendo sido ensinadas explicitamente apenas as relações $\mathrm{AB}$, AC, e DC, eles seriam, então, capazes de emparelhar modelos do Conjunto B com comparaçôes do Conjunto $\mathrm{D}$ (BD), ou modelos do Conjunto D com comparações do Conjunto B (DB). O primeiro objetivo do presente experimento foi realizar estes testes para verificar a emergência das classes de estímulos com quatro membros, ABCD.

Spradlin, Cotter, e Baxley (1973) demonstraram com sucesso a emergência de relações análogas a DB na Figura 2 mas não testaram BD. Uma vez que as relações $\mathrm{DB}$ não exigiam a simetria de $\mathrm{DC}$, mas as relações $\mathrm{BD}$ exigiam (um ponto a ser elaborado mais tarde), tanto as relações $\mathrm{DB}$ quanto as $\mathrm{BD}$ foram necessárias para demonstrar que os procedimentos geraram classes de quatro membros. $\mathrm{O}$ presente experimento também estendeu os resultados de Spradlin, Cotter, e Baxley testando a habilidade dos sujeitos em nomear os estímulos e realizar outras discriminações condicionais além das discriminações $\mathrm{DB}$ e $\mathrm{BD}$. Por exemplo, o treino de AC e DC poderia estabelecer o triângulo ACD na parte inferior da Figura 2, tornando possível, mais uma vez, testar a equivalência avaliando simultaneamente a simetria e a transitividade. Contudo, os testes de equivalência nos triângulos superior e inferior diferiram em pelo menos dois aspectos. Primeiro, as relações explicitamente ensinadas no triângulo superior, $\mathrm{AB}$ e $\mathrm{AC}$, compartilhavam os mesmos modelos; relações análogas no triângulo inferior, AC e DC, compartilharam as mesmas comparações, como o Teste B na Tabela 1. Contudo, a lógica dos testes combinados era similar. Se as relações DC eram simétricas, de forma que a condicionalidade também se mantinha para $\mathrm{CD}$, então $\mathrm{AC}$ e $\mathrm{CD}$ poderiam produzir AD por transitividade; os sujeitos seriam capazes de emparelhar modelos auditivos do Conjunto A com letras de comparação do Conjunto D. Portanto, adicionalmente ao teste das classes de quatro membros $\mathrm{ABCD}$, o presente experimento também testou a emergência de duas classes de estímulos com três membros $\mathrm{ABC}$ e ACD. Os testes para as relações BC 
e $\mathrm{CB}$ avaliaram as classes $\mathrm{ABC}$; os testes para as relaçôes $\mathrm{AD}$ avaliaram as classes $\mathrm{ACD}$.

Uma segunda diferença entre os triângulos superior e inferior na Figura 2 provém da impossibilidade de apresentar vários estímulos auditivos de comparação simultaneamente sem alterar a inteligibilidade individual de cada um deles. Esta característica técnica do procedimento de discriminação condicional utilizado impediu a validação das simetrias $\mathrm{AB}$ e $\mathrm{AC}$ que fosse independente dos testes combinados de simetria/transitividade. Testar BA ou CA exigiria a apresentação consecutiva ao invés de simultânea dos estímulos de comparação auditivos. Uma modificação tão marcante do procedimento, embora plausível, teria interrompido, naquele momento, a continuidade do programa experimental. No triângulo inferior, as relações DC envolveram apenas estímulos visuais e puderam ser testadas quanto à simetria independentemente do teste combinado. $\mathrm{O}$ presente experimento, portanto, testou relações de equivalência não apenas por meio de testes combinados de simetria/transitividade, mas também realizou a avaliação independente da simetria possibilitada pelo triângulo inferior da Figura 2.

$\mathrm{O}$ desenvolvimento de equivalência em todos os três conjuntos de discriminações condicionais explicitamente ensinadas - $\mathrm{AB}, \mathrm{AC}$, e DC - deverá gerar seis conjuntos de novos desempenhos de emparelhamento com o modelo, resumidos pelas setas tracejadas na Figura 2. O experimento testou todas estas possibilidades. Os sujeitos foram também testados quanto à nomeação oral. A nomeação acurada das letras dos Conjuntos B e C era esperada desde que relações condicionais entre estas letras e seus estímulos auditivos correspondentes foram explicitamente ensinadas. A nomeação do Con- junto D foi menos precisamente previsível visto que nenhuma relação direta entre as letras do Conjunto D e os nomes ditados do Conjunto A foi explicitamente ensinada.

\section{MÉTODO}

\section{Sujeitos}

Oito crianças normais, todas do sexo masculino exceto o Sujeito A.D., participaram do experimento. As idades dos sujeitos (anos-meses) no momento em que completaram o treino e foram submetidos aos seus primeiros testes de relaçôes de equivalência eram: 5-0 (A.D.), 5-9 (J.L. e J.O.), 6-3 (D.B.), 6-5 (E.M.), 6-11 (D.W.), 7-4 (E.W.), e 7-5 (I.C.). Os Sujeitos A.D., J.L., D.B, e E.M. freqüentavam o jardim de infância, e os sujeitos J.O, D.W., EW., e I.C. estavam na primeira série (first grade). Outros dados educacionais ou de testes não estavam disponíveis. Todas as crianças tinham ao menos um dos pais que havia completado o nível médio (high school), e todas, exceto os Sujeitos A.D. e J.O., tinham ao menos um dos pais que tinham ido além do nível médio (high school). Cada criança, recrutada por meio de anúncios em um jornal local, vinha ao laboratório vários dias por semana acompanhada por um dos pais, que era remunerado após cada sessão. $\mathrm{O}$ número total de sessões, cada uma com duração de 15 a 30 minutos, variou porque as crianças diferiram na quantidade de treino necessário para aprender e manter as discriminações condicionais de linha de base.

\section{Equipamentos e Procedimentos Gerais}

A criança sentava-se à frente de uma matriz de estímulo-resposta de nove chaves translúcidas (janelas), sobre as quais os estímu- 
los eram projetados a partir da parte posterior. Os estímulos de cada tentativa foram fotografados em um único slide, e obturadores (shutters) operados por solenóides foram montados entre o projetor e as janelas. As janelas, cada uma com $7,3 \mathrm{~cm}$ de diâmetro, foram organizadas em um círculo de oito, com a nona janela no centro (Figura 3). O diâmetro do arranjo circular das janelas era $32,7 \mathrm{~cm}$; a distância centro-a-centro entre as janelas adjacentes no perímetro era de $9,5 \mathrm{~cm}$, e era de $12,7 \mathrm{~cm}$ entre a janela do centro e cada um a das outras. Os estímulos modelo sempre apareciam no centro, e os estímulos de comparação nas janelas externas, mas o presente experimento não utilizou as três janelas externas superiores (sombreadas na Figura 3). Sempre que a criança pressionava uma das janelas, um dispositivo elétrico (interruptor de limite) enviava um sinal para o equipamento de programação, para os contadores de impulso, e para um registrador de operações com 20 canetas.

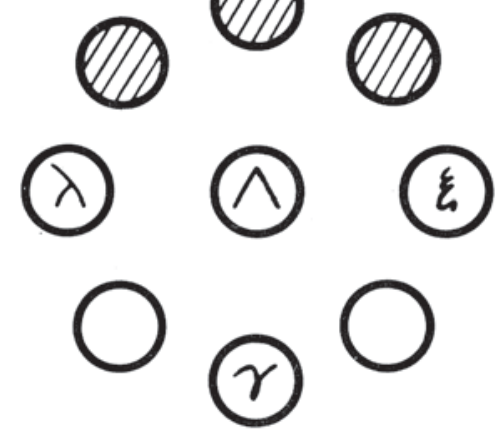

Figura 3 - Representação esquemática da matriz estímulo-resposta, ilustrando um modelo do Conjunto B (janela do centro) e as três comparaçóes do Conjunto C (janelas externas). As posiçôes dos estímulos e das janelas em branco variavam de tentativa para tentativa, mas os estímulos nunca apareciam nas três janelas superiores.

Cada tentativa começava com um estímulo modelo. Os modelos visuais, letras gregas desenhadas em preto sobre um fundo branco, apareciam na janela do centro. Modelos auditivos, os nomes das letras gregas, eram ditados por meio de um gravador (master tape) e eram repetidos em intervalos de $2 \mathrm{~s}$ por uma fita contínua (Fletcher, Stoddard \& Sidman, 1971); a janela do centro era iluminada mas permanecia em branco. Cada modelo, visual ou auditivo, permanecia presente por toda a tentativa (emparelhamento simultâneo), e a duração das tentativas não tinha qualquer limite. Os modelos visuais e auditivos nunca ocorriam em uma mesma tentativa.

Nas tentativas de emparelhamento com o modelo, após o modelo ser apresentado o sujeito deveria pressionar a janela do centro para fazer com que os estímulos de comparação aparecessem nas janelas externas. Até os estímulos modelos ditados exigiam esta "resposta de observação", porém pressionar a janela central em branco não produzia os estímulos de comparação até que, no mínimo, uma palavra modelo completa fosse reproduzida. Em nenhuma tentativa eram apresentados mais do que três estímulos de comparação; pelo menos duas das cinco janelas de comparação ativas ficavam em branco em cada tentativa, como indicado na Figura 3. As posições das janelas de comparação correta, incorreta e em branco variavam de tentativa para tentativa. Nas seqüências que incluíam apenas dois estímulos modelos diferentes, não mais do que três tentativas com o mesmo modelo poderiam ser apresentadas consecutivamente. Com mais do que dois modelos, todos os possíveis tipos de tentativas - combinações entre modelo e comparação - deveriam ocorrer antes que qualquer um deles pudesse se repetir. Além disso, todas as cinco janelas de comparação ativas tinham que ser programadas como janelas corretas antes que qualquer uma delas pudesse ser uma janela correta novamente. 
Com estas exceções, todos os tipos de tentativas e todas as janelas corretas eram igualmente prováveis em tentativas sucessivas.

Após os estímulos de comparação aparecerem, os sujeitos deveriam pressionar uma janela de comparação. A menos que uma probabilidade de reforço reduzida ou uma sonda em extinção (ver abaixo) impedisse o reforço, escolhas corretas eram seguidas por sons de sinos, desaparecimento de todos os estímulos, liberação de uma moeda ${ }^{4}$ dentro de um recipiente aberto situado abaixo e à esquerda da matriz de janelas, e por um intervalo entre tentativas de 1,5 s. Nem os sons nem as moedas seguiam uma escolha incorreta. As crianças guardavam todas as moedas que recebiam.

Qualquer pressão a uma das janelas durante o intervalo entre tentativas adiava a apresentação do próximo modelo por 1,5 s. Uma vez que o modelo fosse apresentado, o sujeito não podia produzir os estímulos de comparação pressionando simultaneamente as janelas do modelo e de uma comparação; após qualquer resposta simultânea, o sujeito deveria soltar ambas as janelas antes que uma pressão ao estímulo modelo pudesse ser efetiva. Quando as comparações eram apresentadas, pressões no modelo não tinham mais quaisquer conseqüências programadas, mas se o sujeito pressionava simultaneamente janelas de comparação correta, incorreta ou em branco, a tentativa era considerada como incorreta. A programação do equipamento especificava arbitrariamente o que era simultâneo esperando para definir uma resposta quando o sujeito soltava a janela por 0,2 $s$; pressionar uma outra janela durante a pressão precedente, ou nos $2 \mathrm{~s}$ após soltar a janela, definia uma resposta como simultânea.
Nos testes de nomeação oral, o sujeito tinha simplesmente que responder à instrução: "Diga-me o que você vê", ou "O que é isto?". A criança não pressionava nenhuma janela, e apenas os modelos eram apresentados, sem qualquer uma das comparações. Após cada resposta oral o experimentador, sentado atrás da criança, pressionava um interruptor manual para iniciar o intervalo entre tentativas e a mudança de slides. Nenhum som ou moeda era apresentado, mesmo para nomes corretos (veja abaixo). As sessões de teste eram registradas em fita magnética, e o experimentador também registrava as respostas de nomeação da criança durante os testes. A transcrição de cada fita por uma secretária, na ausência dos estímulos visuais aos quais o sujeito tinha respondido, nunca diferiu dos registros do experimentador em mais de uma resposta de nomeação em qualquer teste com 90 tentativas.

\section{Fases de Treino e Teste}

O plano geral do experimento (os detalhes são apresentados abaixo) foi, A: primeiro, familiarizar as crianças com os procedimentos e confirmar a habilidade delas em fazer discriminações condicionais com estímulos visuais e com estímulos auditivos e visuais a partir de pré-testes com estímulos presumivelmente familiares, cores e nomes de cores. A seguir, testar o emparelhamento por identidade com todas as letras gregas usadas no experimento. Estas tarefas de emparelhamento letra-letra (modelo-comparação) serviram como testes de emparelhamento com o modelo generalizado para a reflexividade. B: em seguida, ensinar às crianças os três conjuntos de relações identificados na Figura 2 pelas setas contínuas, $\mathrm{AB}, \mathrm{AC}$, e DC. Isto estabeleceu as linhas de base para

4 Os autores utilizaram 1 penny que corresponde a um centavo de dólar (US\$ 0,01). Optou-se nesta tradução por utilizar apenas a denominação "uma moeda" sem a especificação do seu valor. 
os testes de simetria e transitividade. C: finalmente, sem treino adicional, avaliar o desempenho das crianças nos seis conjuntos de relações identificadas pelas setas tracejadas na $\mathrm{Fi}$ gura 2, DB, BD, AD, BC, CB, e CD. A emergência destas novas relações, ou a falha na emergência delas, provaria se as relações condicio-nais explicitamente ensinadas eram, também, ou não relações de equivalência, e se os desempenhos poderiam ser chamados de “emparelhamento com o modelo". Além disso, testar as repostas de nomeação oral das crianças aos estímulos dos Conjuntos B, C e D.

A Tabela 2 ilustra a seqüência planejada. Todos os sujeitos passaram pelas Fases A (Prétestes) e B (Treino) na ordem em que estão indicadas. Ao final da Fase B as crianças estavam realizando os três conjuntos de discriminações condicionais de linha de base, $\mathrm{AB}, \mathrm{AC}$, e $\mathrm{CD}$, com altos níveis de precisão, embora apenas uma pequena proporção das tentativas

\section{Tabela 2}

Seqüência das fases de treino e teste. Os rótulos, $\mathrm{AB}, \mathrm{AC}, \mathrm{DC}$, etc, referem-se às relaçôes modelo - comparação diagramadas na

Figura 2.

A.Pré-testes - Emparelhamento com o Modelo

1. Cores como modelos e cores como comparaçóes (Identidade)

2.Nomes de cores como modelo (ditado) e cores como comparaçóes

3.Letras Gregas como modelos e comparaçóes (Identidade)

B. Treino - Emparelhamento com o Modelo

1.AB: Modelos do Conjunto A (ditado) e comparaçóes do Conjunto B

2.AC: Modelos do Conjunto A (ditado) e comparaçóes do Conjunto C

3.AB e AC: Tentativas das Fases de Treino 1 e 2 misturadas

4.DC: Modelos do Conjunto D (visual) e comparaçóes do Conjunto C

5.AB, AC, e AD: Tentativas das Fases de Treino 3 e 4 misturadas

6.Reduçăo gradual da probabilidade de reforço

C. Testes Finais - Emparelhamento com o Modelo; Nomeaçáo Oral

1.DB: Sondas de equivalência de 4 estágios, com linha de base $\mathrm{AB}$,

AC, e DC

2.BD: Sondas de equivalência de 4 estágios, com linha de base $\mathrm{AB}$, $\mathrm{AC}, \mathrm{e} \mathrm{DC}$

3.AD: Sondas de equivalência de 3 estágios, com linha de base $\mathrm{AC}$ e DC

4.BC: Sondas de equivalência de 3 estágios, com linha de base $\mathrm{AB}$ e AC

5.CB: Sondas de equivalência de 3 estágios, com linha de base de $\mathrm{AB}$ e $\mathrm{AC}$

6.CD: Sondas de simetria das relaçóes DC, com linha de base DC 7.Nomeação de B, C, e D corretas resultassem em reforçamento (ver abaixo). A seguir, na Fase C (Testes Finais), as tentativas de sonda não reforçadas, inseridas entre tentativas de linha de base raramente reforçadas, consistiam nos testes de simetria e transitividade, avaliando assim a formação de relaçôes de equivalência na linha de base.

\section{Pré-testes}

Após a liberação de duas ou três moedas, suficientes para realizar o treino com o dispensador de moedas, o experimentador apresentava instrução não verbal ao pressionar adequadamente as janelas em várias tentativas corcor (cor como modelo e cor como comparações, com a cor do modelo igual à cor da comparação correta). Então, cada sujeito imitava o experimentador, até atingir o critério de 90\% de acertos em um bloco de 25 tentativas corcor (Fase A1), seguido por um critério de desempenho similar no emparelhamento de nomes de cores ditados como modelos com cores como comparações (Fase A2). Estes primeiros testes com as cores estabeleceram a habilidade das crianças em executar os procedimentos experimentais. No procedimento final de pré-teste (Fase A3) os estímulos eram as letras gregas apresentadas na Figura 2. Nas tentativas individuais o modelo e a comparação correta eram idênticos, e as duas comparações incorretas eram sempre os outros membros do mesmo conjunto (B, C, ou D); comparações de conjuntos diferentes nunca apareceram juntas. Este emparelhamento de identidade avaliou o emparelhamento com o modelo generalizado e, portanto, serviu como um teste para a reflexividade.

\section{Procedimentos de Treino e Manutenção}

$\mathrm{O}$ treino dos três conjuntos de discriminaçôes condicionais de linha de base ocorreu 
de acordo com a seqüência resumida na Tabela 2, Fases B1 a B6. Contudo, cada uma das fases de treino foi composta por uma série de passos cuidadosamente programados.

Passos de Treino. As Figuras 4 e 5 descrevem os estímulos modelo e de comparação que compõem os tipos de tentativas de cada passo. Começando com as relações $\mathrm{AB}$, inicialmente as crianças tinham que emparelhar apenas dois modelos ditados, A1 e A2, com letras de comparação B1e B2. Estas duas letras de comparação, uma correta e a outra incorreta, apareciam em cada tentativa, como ilustrado na primeira subdivisão da Figura 4 (Tarefa AB12). As crianças alternavam entre seis blocos de 20 tentativas balanceadas até alcançarem no mínimo 19 tentativas corretas (19 acertos) em um bloco. Então, no segundo passo, as crianças passavam por blocos de 20 tentativas com outro par de modelos e comparaçôes corretas, emparelhando A1 e A3 com B1e B3 (Figura 4, Tarefa AB13) até alcançarem o mesmo critério. Ambos os passos incluíam o Modelo A1 e a Comparação B1. No terceiro passo, as crianças aprendiam a emparelhar o par final de modelos, A2 e A3, e comparações B2 e B3 (Tarefa AB23). Cada uma destas combinações - modelo e comparação correta - já tinham sido apresentadas em um par diferente no Passo 1 ou 2.

Nestes três primeiros passos, as tentativas apresentavam apenas dois estímulos de comparação (balanceados em relação à posição das janelas em que apareciam), um relacionado condicionalmente ao modelo presente, e o outro ao segundo modelo. $\mathrm{O}$ quarto passo de treino AB (Tarefa AB123) misturava os três modelos nos blocos de 30 tentativas, e em cada tentativa eram apresentadas as três comparações, uma correta e duas incorretas. Quando as crianças alcançavam o critério de no mínimo 29 tenta-

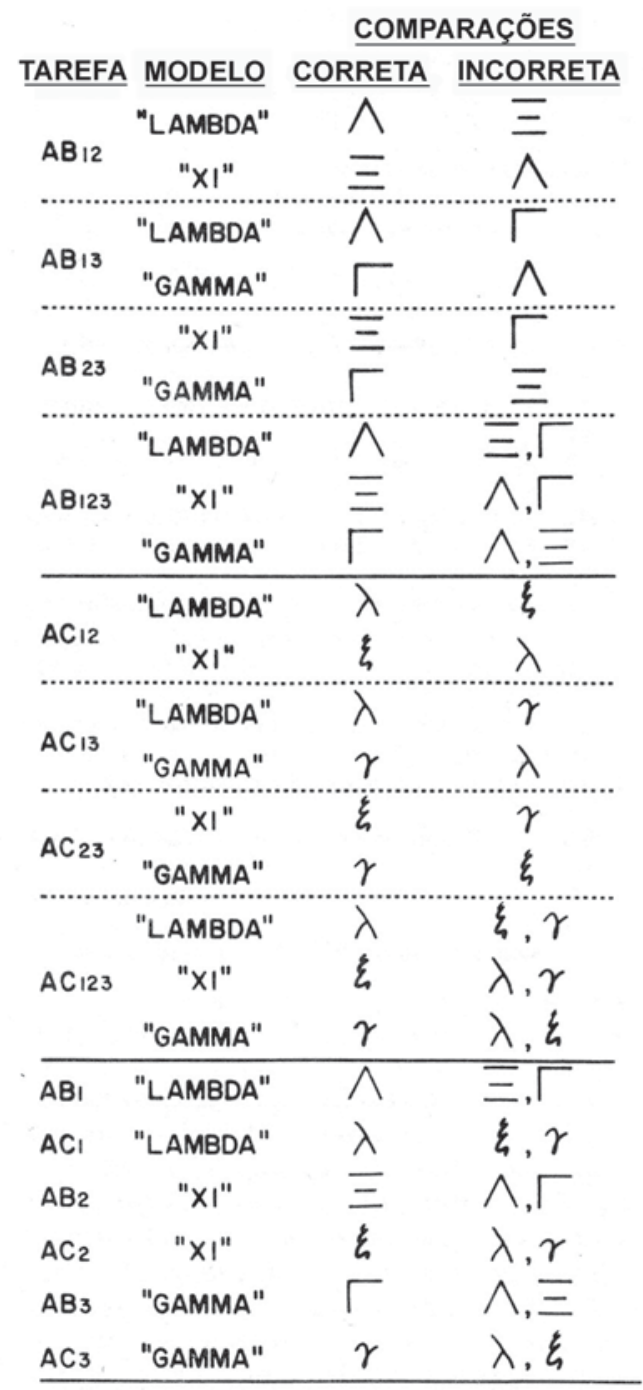

Figura 4 - Cada linha descreve um tipo de tentativa - estímulo modelo com as comparaçốes corretas e incorretas. Cada uma das três partes principais (delimitadas pelas linhas contínuas) mostra os tipos de tentativa utilizados nas Fases de Treino B1, B2 e B3 (Tabela 2) - primeiro as relações AB, depois $\mathrm{AC}$, e então as duas juntas. As subdivisōes de cada parte mostram os tipos de tentativas utilizados em cada passo consecutivo. Os números 1, 2 e 3 se referem aos estímulos auditivos apresentados de cima para baixo na Figura 2 , e aos estímulos visuais apresentados da esquerda para direita.

tivas corretas em um bloco, elas aprendiam em seguida as relações AC (Fase B2 na Tabela 2).

As subdivisões centrais da Figura 4 mostram a Fase B2 de treino dividida em passos semelhantes aos da Fase B1. Primeiramente, as crianças aprendiam pares de tentativas do tipo 


\begin{tabular}{|c|c|c|c|}
\hline \multirow[b]{2}{*}{ TAREFA } & \multirow[b]{2}{*}{ MODELO } & \multicolumn{2}{|c|}{ COMPARAÇÕES } \\
\hline & & CORRETA & INCORRETA \\
\hline \multirow{2}{*}{$\mathrm{DC}_{12}$} & $\phi$ & $\lambda$ & $\xi$ \\
\hline & $\sigma$ & $\xi$ & $\lambda$ \\
\hline \multirow{2}{*}{$\mathrm{DC}_{13}$} & 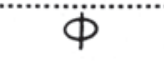 & $\lambda$ & $\gamma$ \\
\hline & $\delta$ & $\gamma$ & $\lambda$ \\
\hline \multirow{2}{*}{$\mathrm{DC}_{23}$} & $\sigma$ & $\xi$ & $\gamma$ \\
\hline & $\delta$ & $\gamma$ & $\xi$ \\
\hline \multirow{3}{*}{$D_{123}$} & $\phi$ & $\lambda$ & $\xi, \gamma$ \\
\hline & $\sigma$ & $\xi$ & $\lambda, \gamma$ \\
\hline & $\delta$ & $\gamma$ & $\lambda, \xi$ \\
\hline$A B_{1}$ & "LAMBDA" & $\wedge$ & 三 \\
\hline$A C I$ & "LAMBDA" & $\lambda$ & \\
\hline $\mathrm{DCl}$ & $\phi$ & $\lambda$ & $\xi, \gamma$ \\
\hline$A B_{2}$ & "XI" & 三 & $\wedge$ \\
\hline $\mathrm{AC}_{2}$ & "xI" & $\xi$ & $\lambda, \gamma$ \\
\hline $\mathrm{DC}_{2}$ & $\sigma$ & $\xi$ & $\lambda, \gamma$ \\
\hline $\mathrm{AB}_{3}$ & "GAMMA" & $\Gamma$ & $\wedge$, 三 \\
\hline $\mathrm{AC}_{3}$ & "GAMMA" & $\gamma$ & $\lambda, \xi$ \\
\hline $\mathrm{DC}_{3}$ & $\delta$ & $\gamma$ & $\lambda, \xi$ \\
\hline
\end{tabular}

Figura 5 - Cada linha descreve um tipo de tentativa - estímulo modelo com as comparaçôes corretas e incorretas. As subdivisōes mostram os tipos de tentativas utilizados em cada passo consecutivo das Fases de Treino B4 e B5 (Tabela 2). As tentativas do tipo DC foram treinadas primeiro (as quatro subdivisōes superiores) e foram então combinadas com as tentativas dos tipos $\mathrm{AB}$ e $\mathrm{AC}$ previamente treinados (subdivisōes inferiores). Os números 1,2 e 3 se referem aos estímulos auditivos apresentados de cima para baixo na Figura 2, e aos estímulos visuais apresentados da esquerda para a direita.

AC com apenas duas comparações por tentativa (Tarefas AC12, AC13, e AC23). Então, eram apresentados blocos de tentativas com três modelos, três comparações por tentativa (Tarefa AC123). A Fase B3 misturou os seis tipos de tentativas $\mathrm{AB}$ e $\mathrm{AC}$, tal como descrito na subdivisão inferior da Figura 4, em blocos de 30 tentativas balanceadas. Alcançando o critério de 29 tentativas corretas em um bloco de 30, as crianças demonstravam que podiam selecionar letras tanto do Conjunto B quanto do Conjun- to $\mathrm{C}$ condicionalmente aos nomes das letras ditados do Conjunto A.

A Fase B4 (Tabela 2) consistia de uma seqüência similar em que as crianças aprenderam as relaçôes DC. As três subdivisões superiores da Figura 5 mostram os três pares de tentativas do tipo DC que as crianças aprenderam primeiro, e a quarta subdivisão mostra as tentativas do tipo DC com três comparações. Finalmente, a Fase 5 misturou os nove tipos de tentativas $\mathrm{AB}, \mathrm{AC}$ e DC (parte inferior da Figura 5) em blocos de 45 tentativas balanceadas. Para completar a Fase B5 as crianças deveriam atingir o critério de 44 tentativas corretas em um bloco de 45. Posteriormente, conjuntos desses nove tipos de tentativas constituiriam uma linha de base sobre a qual tentativas de sonda foram inseridas para avaliar a formação de relaçôes de equivalência.

Probabilidade de reforço. Antes das sondas sem reforço serem inseridas, a probabilidade de reforço nas tentativas corretas de linha de base foi gradualmente reduzida (Fase 6) de 1,00 para 0,20. A seqüência de passos da probabilidade foi 1,00, 0,75, 0,50, 0,40, $0,30,0,20$; os sujeitos tinham que alcançar na linha de base o critério de $90 \%$ de precisão em cada passo antes que a probabilidade pudesse ser reduzida. Ocasionalmente, foi necessário deter uma tendência de decréscimo na precisão aumentando a probabilidade de reforço para, depois, reduzi-la novamente. Uma vez que nenhuma das tentativas de sonda seria reforçada, a probabilidade de reforço nas tentativas de linha de base durante os testes subseqüentes foi aumentada suficientemente para manter a probabilidade total em 0,20. As probabilidades foram controladas por um gerador de probabilidade (BRS/LVE PP-201) com seu ponto de saída 
modificado para não permitir que mais de nove tentativas de linha de base ocorressem sem reforço.

Antes de iniciar qualquer bloco de tentativas em que a probabilidade de reforço seria menor que 1,00 , era dito ao sujeito, "De agora em diante você nem sempre ganhará uma moeda, mas você terá chance de ganhar moedas mais tarde". Então, ao final da sessão, eram apresentadas tentativas de emparelhamento cor-cor, com todas as escolhas corretas reforçadas, na quantidade que faltasse, para completar as tentativas de linha de base corretas que tinham ficado sem reforço.

Manutenção e Revisão. Cada nova sessão de treino começava com uma revisão do desempenho mais avançado que o sujeito tinha adquirido e era necessário atingir o critério de aprendizagem novamente antes de avançar para o próximo passo. Por exemplo, as Tarefas AB12, AB13, e AB23 (Figura 4) eram revisadas no começo de cada sessão de treino até que a criança aprendesse $A B 123$; assim, AB123 era revisado no começo de todas as sessões em que o sujeito estava aprendendo as próximas quatro tarefas; desde que a tarefa final (subdivisão inferior na Figura 4) incluía todos os tipos de tentativas $\mathrm{AB}$ e $\mathrm{AC}$, era necessária a revisão destas tentativas durante a próxima fase de treino; etc. Finalmente, após a redução na probabilidade de reforço, cada sessão em que um teste estava programado começava com uma revisão dos tipos de tentativas que serviriam como linha de base raramente reforçada para a inserção das sondas (cada uma destas linhas de base está descrita abaixo). Para prosseguir com o teste, os sujeitos tinham que alcançar o critério de precisão previsto nesta revisão; se eles não alcançassem, as revisóes continuavam no restante da sessão. Uma criança que falhava freqüentemente em alcançar o critério na revisão retornava a um passo anterior de treino e, depois, novamente avançava na seqüência.

\section{Testes}

As Fases $\mathrm{C} 1$ a $\mathrm{C} 7$ na Tabela 2 resumem os testes que se referem às relações ilustradas na Figura 2.

Equivalência em quatro estágios. $\mathrm{Na}$ Fase $\mathrm{C} 1$ foram inseridas as tentativas DB (modelos do Conjunto D, comparaçōes do Conjunto B) como sondas não reforçadas numa linha de base ocasionalmente reforçada com tentativas $\mathrm{AB}, \mathrm{AC}$ e DC. $\mathrm{Na}$ Fase $\mathrm{C} 2$ foram inseridas as sondas $\mathrm{BD}$ na mesma linha de base. Uma vez que a emergência dos desempenhos $\mathrm{DB}$ e $\mathrm{BD}$ requeria relações condicionais entre quatro conjuntos de estímulos (A, B, C e D), as Fases C1 e C2 na Tabela 2 foram denominadas de "sondas de equivalência em quatro estágios". Esta terminologia de " $n$ estágios" é consistente com um uso similar feito em paradigmas análogos que têm sido amplamente estudados por meio de técnicas de pares associados (e.g., Jenkins, 1963).

A Figura 6 mostra os tipos de tentativas (combinações modelo-comparação) nos testes de quatro estágios, com cada um dos três tipos de sondas $\mathrm{DB}$ abaixo de seus tipos de tentativas pré-requisitos $\mathrm{AB}, \mathrm{AC}$ e $\mathrm{DC}$. Por exemplo, a emergência da relação DB1 (sonda; modelo D1, comparação B1) exigia que os sujeitos tivessem aprendido as relaçôes $\mathrm{AB} 1, \mathrm{AC} 1$, e $\mathrm{AD} 1$ que são mostradas exatamente acima da relação DB1. Na Fase C2, as três sondas BD descritas na parte inferior da Figura 6 substituíram as tentativas DB. Cada teste $\mathrm{DB}$ ou BD continha 120 tentativas, 10 de cada tipo de tentativa (90 de linha de base e 30 de sonda).

Equivalência em três estágios. As Fases C3, C4 e C5 na Tabela 2 resumem as sondas de três 


\section{COMPARAÇÕES}

TAREFA MODELO CORRETA INCORRETA

\begin{tabular}{|c|c|c|}
\hline$A B_{1} \quad$ "LAMBDA" & $\wedge$ & 三, \\
\hline$A C_{1} \quad$ "LAMBDA" & $\lambda$ & \\
\hline$\phi$ & $\lambda$ & \\
\hline DBI(PROBE) $\varnothing$ & $(\wedge)$ & \\
\hline$A B_{2} \quad$ "XI" & 三 & \\
\hline "XI" & $\xi$ & \\
\hline $\mathrm{DC}_{2}$ & $\xi$ & \\
\hline $\mathrm{DB}_{2 \text { (PROBE) } \sigma} \sigma$ & $=$ & \\
\hline AB3 "GAMMA" & & \\
\hline "GAMMA" & $\gamma$ & \\
\hline $\mathrm{DC}_{3}$ & $\gamma$ & $\xi$ \\
\hline DB3(PROBE) $\delta$ & $(\Gamma)$ & $(\Lambda, \Gamma)$ \\
\hline BDI(PROBE) $\wedge$ & $(\phi)$ & $(\sigma, \delta)$ \\
\hline $\mathrm{BD}_{2 \text { (PROBE) }}=$ & $(\sigma)$ & $(\phi, \delta)$ \\
\hline BD3(PROBE) & $(\delta)$ & $(\phi, \sigma)$ \\
\hline
\end{tabular}

Figura 6: Cada linha descreve um tipo de tentativa - estímulo modelo com as comparaçôes corretas e incorretas. A parte superior mostra os tipos de tentativas $\mathrm{AB}, \mathrm{AC}$, e $\mathrm{DC}$ de linha de base e as sondas $\mathrm{DB}$ de quatro estágios utilizadas na Fase de Teste Final C1 (Tabela 2). Cada sonda DB está exatamente abaixo dos seus três tipos de tentativas pré-requisitos. As três linhas na parte inferior mostram as sondas DB durante a Fase de Teste Final C2 (Tabela 2). Os números 1, 2, e 3 se referem aos estímulos auditivos apresentados de cima para baixo na Figura 2 e aos estímulos visuais apresentados da esquerda para a direita. Devido aos fato das tentativas de sonda nunca terem sido reforçadas, os estímulos de comparação corretos e incorretos de sonda estão incluídos entre parênteses.

estágios - aquelas que exigiam dos sujeitos o aprendizado de relações condicionais com três conjuntos de estímulos. As sondas AD (Fase C3) envolveram os conjuntos de estímulo A, C e D (Figura 2). Uma vez que a emergência das relaçóes $\mathrm{AD}$ exigia a aprendizagem somente das relações $\mathrm{AC}$ e $\mathrm{DC}$, as sondas $\mathrm{AD}$ foram inseridas numa linha de base apenas com tentativas AC e DC. A Figura 7 mostra os tipos de tentativas nos testes $\mathrm{AD}$ de três estágios, com cada sonda $\mathrm{AD}$ abaixo de seus tipos de tentativas pré-requisitos $\mathrm{AC}$ e DC. Os testes $\mathrm{AD}$ continham 90
COMPARAÇÕES

TAREFA MODELO CORRETA INCORRETA

\begin{tabular}{|c|c|c|c|}
\hline$A C_{1}$ & "LAMBDA" & $\lambda$ & $\varepsilon, \gamma$ \\
\hline$D C$ & $\phi$ & $\lambda$ & $\xi, \gamma$ \\
\hline$A D_{1}(P R O B E)$ & "LAMBDA" & $(\phi)$ & $(\sigma, \delta)$ \\
\hline $\mathrm{AC}_{2}$ & "xI" & $\varepsilon$ & $\gamma$ \\
\hline $\mathrm{DC}_{2}$ & $\sigma$ & $\xi$ & $\gamma$ \\
\hline$A D_{2}$ (PROBE) & "xI" & $(\sigma)$ & \\
\hline$A C_{3}$ & "GAMMA" & $\gamma$ & \\
\hline$D C_{3}$ & $\delta$ & $\gamma$ & \\
\hline$A D 3$ (PROBE) & ) "GAMMA" & $(\delta)$ & $(\Phi, \sigma)$ \\
\hline
\end{tabular}

Figura 7: Cada linha descreve um tipo de tentativa - estímulo modelo com as comparaçôes corretas e incorretas - utilizada na Fase de Teste Final C3. Cada sonda $\mathrm{AD}$ de três estágios está exatamente abaixo dos seus dois tipos de tentativas pré-requisitos de linha de base AC e DC. Os números 1, 2, e 3 se referem aos estímulos auditivos apresentados de cima para baixo na Figura 2 e aos estímulos visuais apresentados da esquerda para a direita. Devido aos fato das tentativas de sonda nunca terem sido reforçadas, os estímulos de comparação corretos e incorretos de sonda estão incluídos entre parênteses.

tentativas, 10 de cada tipo de tentativa (60 de linha de base e 30 de sonda).

As sondas de três estágios BC e CB (Fases C4 e C5) exigiam que os sujeitos tivessem aprendido relações condicionais com os Conjuntos de Estímulo A, B e C (Figura 2). Uma vez que a emergência de $\mathrm{BC}$ e $\mathrm{CB}$ demandava apenas $\mathrm{AB}$ e $\mathrm{AC}$ como pré-requisitos, as Fases C4 e C5 foram combinadas em um único teste, com sondas inseridas numa linha de base com tentativas $\mathrm{AB}$ e AC. A Figura 8 mostra os tipos de tentativas, com cada par de sondas $\mathrm{BC}$ e CB localizado abaixo dos tipos de tentativas pré-requisitos $\mathrm{AB}$ e $\mathrm{AC}$. Estes testes combinados BC e CB continham 120 tentativas, 10 de cada tipo (60 de linha de base e 60 tentativas de sonda - 30 sondas BC e $30 \mathrm{CB}$ ).

Simetria. Na Fase C6 (Tabela 2), as sondas $\mathrm{CD}$ testavam a simetria das relaçôes DC. A Figura 9 mostra os tipos de tentativas neste teste de simetria com sondas CD inseridas numa linha de 
base que continha apenas tentativas DC. Os testes $\mathrm{CD}$ continham 60 tentativas, 10 de cada tipo (30 de linha de base e 30 tentativas de sonda).

Nomeação oral. Os testes finais, Fase C7 da Tabela 2, foram de nomeação oral, em que os sujeitos nomeavam em voz alta os estímulos B, C, e D. Os testes de nomeação continham 90 tentativas, com 10 apresentações de cada estímulo visual.

\section{COMPARAÇÕES}

\begin{tabular}{|c|c|c|}
\hline AREFA MODELO & OKREIA & 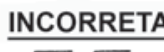 \\
\hline "LAMBDA" & & \\
\hline "LAMBDA" & & \\
\hline BCI(PROBE) $\bigwedge$ & $\lambda$ ) & r) \\
\hline CBI(PROBE) $\lambda$ & 入) & \\
\hline "XI" & & \\
\hline "xi" & & \\
\hline $\mathrm{BC}_{2}$ (PROBE) 三 & $\xi)$ & $, \gamma)$ \\
\hline $\mathrm{CB}_{2 \text { (PROBE) }} \varepsilon$ & & \\
\hline "GAMMA" & & \\
\hline "GAMMA" & $\gamma$ & $\xi$ \\
\hline $\mathrm{BC}_{3}$ (PROBE) & & \\
\hline $\mathrm{CB}_{3}$ (PROBE) $\gamma$ & & \\
\hline
\end{tabular}

Figura 8: Cada linha descreve um tipo de tentativa - estímulo modelo com as comparaçōes corretas e incorretas utilizada na Fase de Teste Final C4 e C5 (Tabela 2), que foram combinadas em um único teste. Cada par de sondas $\mathrm{BC}$ e CD está exatamente abaixo dos seus dois tipos de tentativas prérequisitos de linha de base $\mathrm{AB}$ e $\mathrm{AC}$. Os números 1, 2, e 3 se referem aos estímulos auditivos apresentados de cima para baixo na Figura 2 e aos estímulos visuais apresentados da esquerda para a direita. Devido aos fato das tentativas de sonda nunca terem sido reforçadas, os estímulos de comparação corretos e incorretos de sonda estão incluídos entre parênteses.

Seqüencia de testes. A Tabela 3 mostra a seqüência de testes para cada sujeito. Seis sujeitos passaram pela Fase C com pequenas variações na ordem apresentada na Tabela 2. Dois sujeitos, J.O. e J.L., necessitaram de desvios maiores desta seqüência; seus testes e dados serão indicados separadamente.
Tabela 3

Seqüência de testes para cada sujeito

\begin{tabular}{|c|c|c|c|c|c|c|}
\hline \multirow[t]{2}{*}{ Sujeitos } & \multicolumn{2}{|c|}{ Quatro estágios } & \multicolumn{2}{|c|}{ Três estágios } & \multicolumn{2}{|c|}{ Simetria } \\
\hline & DB & $\mathrm{BD}$ & $\mathrm{AD}$ & $\mathrm{BC}-\mathrm{CB}$ & $\mathrm{AC}$ & Nomeaçáo \\
\hline E.W. & 1 & 2 & 3 & 4 & - & 5 \\
\hline A.D. & 1 & 2 & 3 & 4 & 5 & - \\
\hline D.B. & 2 & 1 & 3 & 4 & 5 & 6 \\
\hline E.M. & 1 & 2 & 4 & 5 & - & 3 \\
\hline I.C. & 1 & 2 & 5 & 4 & 6 & 3 \\
\hline D.W. & 1 & 2 & 3 & 4 & 5 & 6 \\
\hline J.O. & 1 & 2 & (ver & texto) & & \\
\hline J.L. & 1 & & 2 & 3 & & er texto) \\
\hline
\end{tabular}

\section{RESULTADOS}

Cada coluna de barras na Figura 10 representa o teste de emparelhamento com o modelo e os escores de linha de base para um dos seis sujeitos. Os cabeçalhos das colunas (BD,..., DC) referem-se às relações diagramadas na Figura 2. Embora não tenha ocorrido reforçamento diferencial nas tentativas de sonda, as respostas indicativas de relações de equivalência foram arbitrariamente designadas como corretas na sumarização dos resultados das tentativas de sonda. As três barras à extrema direita de cada coluna combinam os escores de cada tipo indicado de tentativa de linha de base ao longo de todos os testes (Figuras 6 a 9). As primeiras seis barras (apenas cinco para os sujeitos E.W. e E.M.) representam, cada uma, o escore numa tentativa de sonda de equivalência em quatro estágios, em três estágios, ou teste de simetria.

Os desempenhos de linha de base foram uniformemente excelentes. Uma análise mais refinada de cada relação de linha de base em seus três tipos de tentativas (por exemplo, aqueles listados na parte inferior da Figura 5) mostrou que estas crianças raramente faziam dois erros, e nunca mais que dois, em 10 tentativas de linha de base de qualquer tipo. A inserção de tentativas de sonda não familiares entre os tipos de tentativas explicitamente ensinadas não causou ruptura nas linhas de base. 
COMPARAÇÕES

TAREFA MODELO CORRETA INCORRETA

\begin{tabular}{|c|c|c|}
\hline$\overline{D C_{1}} \phi$ & $\lambda$ & $\xi, \gamma$ \\
\hline $\mathrm{CD}_{\text {I (PROBE) }} \lambda$ & $(\phi)$ & $(\sigma, \delta)$ \\
\hline$D_{2}$ & $\xi$ & \\
\hline $\mathrm{CD}_{2}$ (PROBE) $\xi$ & $(\sigma)$ & \\
\hline $\mathrm{DC}_{3}$ & $\gamma$ & \\
\hline $\mathrm{CD}_{3 \text { (PROBE) }} \gamma$ & $(\delta)$ & $(\Phi, \sigma)$ \\
\hline
\end{tabular}

Figura 9: Cada linha descreve um tipo de tentativa - estímulo modelo com as comparaçōes corretas e incorretas - utilizada na Fase de Teste Final C6 (Tabela 2). Cada sonda de simetria está abaixo do seu tipo de tentativa prérequisito de linha de base DC. Os números 1, 2, e 3 se referem aos estímulos visuais apresentados da esquerda para a direita. Devido aos fato das tentativas de sonda nunca terem sido reforçadas, os estímulos de comparação corretos e incorretos de sonda estão incluídos entre parênteses.

As crianças também se comportaram de uma forma notavelmente consistente em tentativas de sonda. Nas sondas de quatro estágios para as relações BD e DB, apenas o sujeito I.C. selecionou uma letra "incorreta" não mais do que quatro vezes em 30 tentativas de sonda. Todos os sujeitos distribuíram seus erros de forma relativamente igual entre os tipos de tentativas. Nos testes AD de três estágios, cinco das crianças variaram de zero a dois erros em 30 tentativas de sonda; o sujeito I.C., contudo apresentou, nestes testes, uma indicação de relações de equivalência não completamente estabelecidas. Embora ele tenha cometido apenas cinco erros nas 30 sondas $\mathrm{AD}$, quatro erros ocorreram no conjunto de 10 tentativas com o estimulo "gamma" ditado como modelo, e três dentre estes quatro foram seleções da letra apropriada para "lambda" (Figura 7). Nas sondas em quatro estágios das relações $\mathrm{BC}$ e $\mathrm{CB}$, e nas sondas de simetria $\mathrm{CD}$, o sujeito I.C. foi novamente o único, dentre as seis crianças, a apresentar aproximadamente quatro erros em qualquer conjunto de 30 tentativas, erros não concentrados, contudo, em qualquer tipo particular de tentativa.

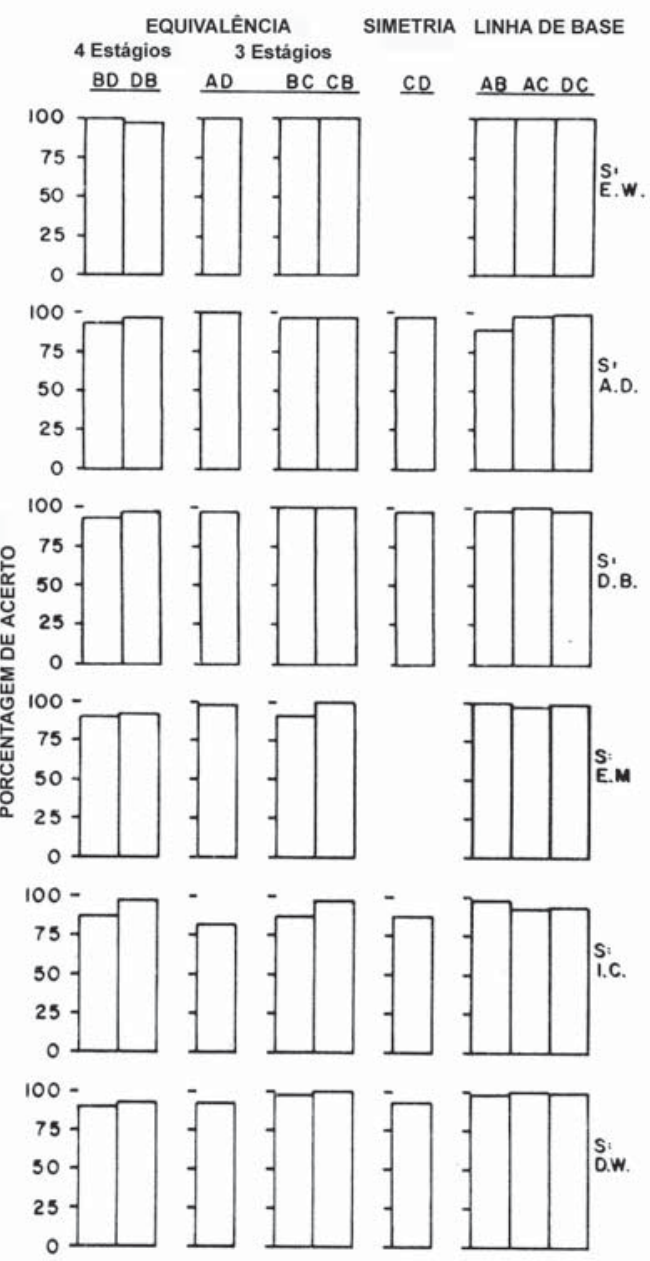

Figura 10: Cada coluna de barras apresenta os escores de uma criança nas sondas de equivalência (BD e DB de quatro estágios; $\mathrm{AD}, \mathrm{BC}$, e CB de três estágios), sondas de simetria (CD), e tentativas de linha de base (AB, AC, e DC) resumidas na Tabela 2, Fase de Teste Final. Os escores de sonda representam testes individuais, e os escores de linha de base estão agrupados para todos os testes. Duas crianças não realizaram testes de simetria.

Quando solicitados a identificar as letras, os sujeitos as nomearam quase perfeitamente, nenhum deles apresentando mais do que dois erros no teste com 90 tentativas. Em cada conjunto de letras mostrado na Figura 2 (B, C, e D), as crianças denominaram consistentemente a letra da esquerda de "lambda", a do centro de "xi", e a da direita de "gamma" (a correlação entre os membros da classe e a posição das letras na Figura 2 é simplesmente um recurso de apresentação; durante os testes de 
nomeação a letra estava sempre na janela do centro, e durante os testes de emparelhamento com o modelo as posiçôes das letras de comparação variavam de tentativa para tentativa). Esta consistência foi perfeita nas tentativas com os estímulos D, muito embora a seleção que as crianças faziam dos estímulos D condicionalmente aos nomes ditados (AD) nunca tenha sido reforçada.

Contudo, o sujeito E.W., diferiu de todos os outros em sua maneira de responder aos estímulos D. A Tabela 4 reproduz a primeira metade (45 tentativas) do seu teste de nomeação oral, incluindo as instruções (ao contrário da transcrição real, a Tabela 4 identifica o estímulo em cada tentativa). Embora o sujeito E.W. tenha utilizado todos os nomes esperados, suas respostas indicaram que os estímulos $\mathrm{D}$ diferiam dos estímulos $\mathrm{B}$ e C; é possível examinar a Tabela 4 e identificar as tentativas D, mesmo sem olhar quais tentativas continham estímulos D. Na tentativa 2, onde ocorreu a primeira apresentação de uma letra do conjunto D, a criança demonstrou dúvida, deixando mesmo de aventurar-se até que fosse fornecida uma dica. Embora as respostas posteriores não fossem tão demoradas, ele expressou alguma dúvida sobre o nome de cada estímulo D subseqüente. Em contraste, com exceção apenas da Tentativa 15 , ele nomeou os estímulos $\mathrm{B}$ e $\mathrm{C}$ sem restrição. Nas tentativas 40 e 41 , a própria criança enfatizou a diferença. Durante a segunda metade do teste, mais 45 tentativas, o sujeito E.W. continuou consistentemente a indicar incerteza na nomeação dos estímulos D.

Se as classes de quatro membros, reveladas pelos testes em quatro estágios $\mathrm{BD}$ e $\mathrm{DB}$, originaram-se das relações de equivalência, os dados também devem apresentar certas consistências internas. Uma referência à Figura 2 ajudará a clarificar os pré-requisitos para as classes de quatro membros. Dadas as relaçôes explicitamente ensinadas, $A B, A C$, e DC, o seguinte paradigma de transitividade (TR1) constituiu a rota mais simples para a emergência das relações DB, nas quais as crianças emparelharam modelos do Conjunto D com comparações do Conjunto B:

(TRl) Se DC e CB, então DB.

Qualquer criança capaz de fazer DB também deveria ser capaz de fazer DC e CB. As relações DC explicitamente ensinadas foram facilmente verificadas na linha de base, mas CB, nunca explicitamente ensinada, deveria ser testada. As seis crianças que foram capazes de fazer a relação DB apresentaram bom desempenho nos testes CB.

As relações $\mathrm{CB}$, nas quais as crianças emparelhavam modelos do Conjunto $\mathrm{C}$ com comparaçóes do Conjunto B, poderiam ter emergido pelo paradigma de transitividade:

(TR2) Se CA e AB, então CB.

Qualquer criança capaz de fazer CB também deveria ser capaz de CA e AB. Novamente, as linhas de base verificaram as relações $\mathrm{AB}$. As relações CA poderiam ter emergido pelo paradigma de simetria SY1:

(SY1) Se AC, então CA.

Os procedimentos utilizados impediram testes diretos de simetria das relações auditivovisuais, $A B, A C$, e $A D$, porque seria necessário que as crianças emparelhassem modelos visuais com comparaçôes auditivas; a apresentação de várias comparações auditivas simultaneamente era impraticável. As relaçôes CA, indicativas de simetria $\mathrm{AC}$, portanto, não foram testadas.

$\mathrm{O}$ outro teste de quatro estágios, $\mathrm{BD}$, necessitou de diferentes pré-requisitos. $\mathrm{O}$ emparelhamento de modelos do Conjunto B com comparações do Conjunto D poderia ter emergido por transitividade por meio do paradigma: (TR3) Se BC e CD, então BD. 


\section{TABELA 4}

Respostas do Sujeito E.W. nas primeiras 45 tentativas de nomeação oral, incluindo a interação entre o Sujeito (S) e o Experimentador

(E) no pré-teste. As tentativas estão listadas sucessivamente, e os estímulos são identificados de acordo com a representação na Figura 2, onde esquerda (1), centro (2), ou direita (3) referem-se aos membros dos Conjuntos B, C, ou D.

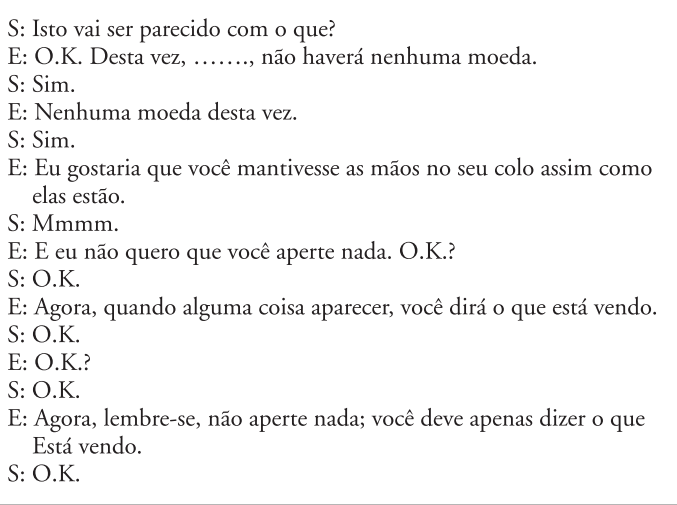

\begin{tabular}{|c|c|c|}
\hline Tentativa & Estímulo & Respostas \\
\hline 1 & $1 \mathrm{C}$ & $\begin{array}{l}\text { S: .................. LAMBDA } \\
\text { E: Você não - Você não deve gritar } \\
\text { desta forma no microfone. Ele irá - } \\
\text { ele irá ouvir você muito bem, O.K.? } \\
\text { S: O.K. }\end{array}$ \\
\hline 2 & $3 \mathrm{C}$ & $\begin{array}{l}\text { S:.......hmmmmmmmmmmm. } \\
\text { Parece alguma coisa como, mas - eu } \\
\text { não sei. É tipo - Bem, eu - realmente } \\
\text { não tenho nenhuma idéia - Uma } \\
\text { pequena idéia, mas eu não sei o que é. }\end{array}$ \\
\hline & & $\begin{array}{l}\text { E: O que éisto? } \\
\text { S: Bem, eu tenho uma - uma leve } \\
\text { idéia de que poderia ser GAMMA. }\end{array}$ \\
\hline 3 & $2 \mathrm{D}$ & $\begin{array}{l}\text { S: hmmmmmmmmmmm. Eu acho } \\
\text { que pode ser XI. }\end{array}$ \\
\hline 4 & $3 \mathrm{C}$ & S: Isto é GAMMA. \\
\hline 5 & $2 \mathrm{~B}$ & S: Isto éXI. \\
\hline 6 & $3 \mathrm{~B}$ & S: Isto é GAMMA. \\
\hline 7 & $1 \mathrm{D}$ & $\begin{array}{l}S: \text { hmmmmmmmmmmm. - Eu } \\
\text { acho que pode ser LAMBDA. }\end{array}$ \\
\hline 8 & $1 \mathrm{~B}$ & S: Isto é LAMBDA. \\
\hline 9 & $2 \mathrm{C}$ & S:ISTOÉXI. \\
\hline 10 & $1 \mathrm{C}$ & S: Isto é LAMBDA. \\
\hline 11 & $2 \mathrm{~B}$ & S: Isto éXI. \\
\hline 12 & $3 \mathrm{C}$ & S: Isto é- GAMMA. \\
\hline 13 & $3 \mathrm{~B}$ & S: Isto é GAMMA. \\
\hline 14 & $2 \mathrm{D}$ & $\begin{array}{l}\text { S: Eu - Eu tenho uma leve impressão } \\
\text { de que pode ser XI. }\end{array}$ \\
\hline 15 & $2 \mathrm{C}$ & S: Eu acho que éXI. \\
\hline 16 & $3 \mathrm{D}$ & $\begin{array}{l}\text { S: Pode ser GAMMA, mas eu náo } \\
\text { estou muito certo. }\end{array}$ \\
\hline 17 & $1 \mathrm{D}$ & $\begin{array}{l}\text { S: Eu - Eu acho - Pode ser } \\
\text { LAMBDA, mas náo estou certo }\end{array}$ \\
\hline 18 & $1 \mathrm{~B}$ & S: Isto é LAMBDA. \\
\hline
\end{tabular}

\begin{tabular}{|c|c|c|}
\hline Tentativa & Estímulo & Respostas \\
\hline 19 & $1 \mathrm{D}$ & $\begin{array}{l}\text { S: Eu prefiro o LAMBDA, mas eu } \\
\text { não estou muito certo. }\end{array}$ \\
\hline 20 & $1 \mathrm{C}$ & S: Isto é LAMBDA. \\
\hline 21 & $2 \mathrm{D}$ & S: Isto pode ser XI. \\
\hline 22 & $2 \mathrm{~B}$ & S: Isto éXI. \\
\hline 23 & $1 \mathrm{~B}$ & S: Isto é LAMBDA. \\
\hline 24 & $3 \mathrm{~B}$ & S: Isto é GAMMA. \\
\hline 25 & $2 \mathrm{C}$ & S: Isto éXI. \\
\hline 26 & $3 \mathrm{C}$ & S: Isto é GAMMA. \\
\hline 27 & $3 \mathrm{D}$ & $\begin{array}{l}\text { S: Mmmmmm. Eu tenho uma le- } \\
\text { leve impressáo de que só pode ser } \\
\text { GAMMA. }\end{array}$ \\
\hline 28 & $2 \mathrm{C}$ & S:XI. \\
\hline 29 & $1 \mathrm{D}$ & $\begin{array}{l}\text { S: Pode ser LAMBDA, mas eu náo } \\
\text { estou certo. }\end{array}$ \\
\hline 30 & $2 \mathrm{~B}$ & S:XI. \\
\hline 31 & $1 \mathrm{C}$ & S: LAMBDA. \\
\hline 32 & $3 \mathrm{C}$ & S: GAMMA. \\
\hline 33 & 1B & S: LAMBDA. \\
\hline 34 & 3B & S: GAMMA. \\
\hline 35 & $2 \mathrm{D}$ & S:XI........... Eu acho. \\
\hline 36 & $3 \mathrm{D}$ & $\begin{array}{l}\text { S: Mmmmmm, Eu acho que pode } \\
\text { ser GAMMA, mas eu năo estou } \\
\text { muito certo. }\end{array}$ \\
\hline 37 & $1 \mathrm{~B}$ & S: LAMBDA. \\
\hline 38 & $2 \mathrm{D}$ & S: Pode ser XI. \\
\hline 39 & $1 \mathrm{D}$ & $\begin{array}{l}\text { S: Parece LAMBDA, mas eu náo } \\
\text { estou muito certo. }\end{array}$ \\
\hline 40 & $3 \mathrm{D}$ & S: Isto pode ser GAMMA \\
\hline 41 & $3 \mathrm{C}$ & S: Isto é GAMMA. \\
\hline 42 & $2 \mathrm{C}$ & S: Isto éXI. \\
\hline 43 & $1 \mathrm{C}$ & S: LAMBDA. \\
\hline 44 & $3 \mathrm{~B}$ & S: GAMMA. \\
\hline 45 & $2 \mathrm{~B}$ & S:XI. \\
\hline
\end{tabular}

Qualquer criança capaz de fazer BD deveria também ser capaz de fazer $\mathrm{BC}$ e $\mathrm{CD}$, embora nenhuma das duas relações tenha sido explicitamente ensinada. As seis crianças que foram capazes de fazer BD também apresentaram bom desempenho nos testes $\mathrm{BC}$ e $\mathrm{CD}$. As relações $\mathrm{BC}$ poderiam ter emergido por transitividade: (TR4) Se BA e AC, então BC.

Aqui, as linhas de base verificaram as relações $A C$. A relação $B A$ indicaria a simetria $A B$ : (SY2) Se $A B$, então $B A$.

Contudo, novamente, a simetria auditivo-visual não poderia ser testada diretamente.

A emergência do segundo pré-requisito de $\mathrm{BD}$, as relaçôes CD (veja TR3), evidenciou que as relações visual-visual DC eram simétricas: (SY3) Se DC, então CD. 
As relaçôes $\mathrm{CD}$, indicativas de simetria $\mathrm{DC}$, foram pré-requisitos não apenas para as relaçôes de quatro estágios $\mathrm{BD}$ (porTR3), mas também para as relações de três estágios AD. A rota mais simples para a emergência das relações AD foi:

\section{(TR5) Se AC e DC, então AD.}

Os desempenhos de linha de base verificaram as relações AC, e as crianças que mostraram ser capazes tanto de $\mathrm{AD}$ quanto de $\mathrm{BD}$, também apresentaram bom desempenho no teste CD (dois sujeitos não realizaram o teste CD; veja a Figura 10).

Todas as crianças, portanto, cujos desempenhos DB e BD indicaram o estabelecimento de classes de estímulo com quatro membros, também demonstraram as consistências internas necessárias em seus outros dados. As relações pré-requisito de nível inferior estavam intactas.

Os sujeitos J.L. e J.O. falharam em replicar os resultados das outras seis crianças; seus desempenhos BD e DB revelaram a ausência das propriedades transitivas (TR3 e TR1) requeridas pelas relaçóes de equivalência de quatro estágios. A ausência de simetria ou transitividade de nível inferior poderia ter sido responsável pela falha na emergência de relações de nível superior? Testes adicionais aplicados às duas crianças que não exibiram classes de estímulos com quatro membros estão resumidos seqüencialmente na Tabela 5 .

O sujeito J.L., que falhou em confirmar a equivalência de quatro estágios antes da decisão de realizar um acompanhamento sistemático, não recebeu todos os testes necessários para uma avaliação completa das relações entre desempenhos de nível superior e inferior. A parte superior da Tabela 5 mostra que ele alcançou apenas $47 \%$ em seu primeiro teste DB de quatro estágios, e 40\% quando testado para as relações AD de três estágios (Testes $1 \mathrm{e}$ 2). Então, ele alcançou 97 e 93\% nas outras sondas de três estágios, BC e CB (Teste 3). A

Tabela 5

Escores dos Sujeitos J.L. e J.O. (porcentagem de acerto) nos testes sucessivos. As denominações das colunas referem-se às relaçôes da Figura 2. Nomeação indica os testes de nomeação oral com os estímulos dos Conjuntos B, C e D. A partir do Teste 8 do Sujeito J.O. as tentativas de linha de base e de sonda não foram reforçadas.

\begin{tabular}{|c|c|c|c|c|c|c|c|c|c|c|c|}
\hline \multirow{3}{*}{ Sujeitos } & \multirow{3}{*}{$\begin{array}{l}\mathrm{N}^{\circ} \text { do } \\
\text { teste }\end{array}$} & \multicolumn{5}{|c|}{ Equivalência } & \multirow{3}{*}{$\begin{array}{l}\text { Sime- } \\
\text { tria } \\
\text { CD }\end{array}$} & \multirow{3}{*}{$\begin{array}{l}\text { Nome- } \\
\text { açáo } \\
\text { B,C,D }\end{array}$} & \multirow{2}{*}{\multicolumn{3}{|c|}{ Linha de base }} \\
\hline & & \multicolumn{2}{|c|}{ Quatro estágios } & \multicolumn{3}{|c|}{ Três estágios } & & & & & \\
\hline & & $\mathrm{BD}$ & $\mathrm{DB}$ & $\mathrm{AD}$ & $\mathrm{BC}$ & $\mathrm{CB}$ & & & $\mathrm{AB}$ & $\mathrm{AC}$ & $\mathrm{DC}$ \\
\hline J.L. & 1 & - & 47 & - & - & - & - & - & 100 & 100 & 97 \\
\hline J.L. & 2 & - & - & 40 & - & - & - & - & - & 100 & 97 \\
\hline J.L. & 3 & - & - & - & 97 & 93 & - & - & 100 & 100 & - \\
\hline J.L. & 4 & - & 17 & - & - & - & - & - & 97 & 100 & 100 \\
\hline J.O. & 1 & - & 83 & - & - & - & - & - & 100 & 97 & 100 \\
\hline J.O. & 2 & 50 & - & - & - & - & - & - & 100 & 87 & 97 \\
\hline J.O. & 3 & - & 57 & - & - & - & - & - & 100 & 100 & 90 \\
\hline J.O. & 4 & - & 60 & - & - & - & - & - & 100 & 97 & 100 \\
\hline J.O. & 5 & - & - & 60 & - & - & - & - & - & 100 & 100 \\
\hline J.L. & 6 & - & 43 & - & - & - & - & - & 100 & 100 & 97 \\
\hline J.O. & 7 & - & - & 50 & - & - & - & - & - & 97 & 100 \\
\hline J.O. & $* 8^{*}$ & - & 50 & - & - & - & - & - & 97 & 93 & 100 \\
\hline J.O. & 9 & - & - & - & 57 & 30 & - & - & 97 & 90 & - \\
\hline J.O. & 10 & - & - & - & - & - & 37 & - & - & - & 67 \\
\hline J.O. & 11 & - & - & - & - & - & - & 90 & - & - & - \\
\hline J.O. & 12 & - & 10 & - & - & - & - & - & 83 & 97 & 93 \\
\hline J.O. & 13 & - & - & - & - & - & - & 97 & - & - & - \\
\hline
\end{tabular}


repetição das sondas $\mathrm{DB}$ de quatro estágios (Teste 4) produziu um escore de apenas 17\%. $\mathrm{O}$ sujeito J.L. falhou em demonstrar classes de quatro membros ou classes ACD de três membros (indicadas pelo triângulo inferior na Figura 2), mas certamente mostrou a formação de classes $\mathrm{ABC}$ de três membros (o triângulo superior na Figura 2). Relações DC fortes na linha de base (coluna do lado direito da Tabela 5) e sólidos desempenhos CB (Teste 3) mostraram que os pré-requisitos para a equivalência $\mathrm{DB}$ em quatro estágios (veja TR1) estavam intactos. Os testes de acompanhamento do Sujeito J.L., portanto, não forneceram qualquer explicação óbvia para a falha na emergência da relação DB. Infelizmente, as outras relações de quatro estágios, $\mathrm{BD}$, não foram avaliadas, assim como também não o foram as relações $\mathrm{CD}$, o que teria clarificado a falha na emergência da relação $\mathrm{AD}$ (veja TR5).

O outro sujeito, J.O., realizou uma série de testes de acompanhamento mais adequada (parte inferior da Tabela 5). Seu primeiro teste de quatro estágios produziu $83 \%$ de acerto; ele não apresentou mais do que duas respostas incorretas em 10 oportunidades com qualquer um dos modelos do Conjunto D. Quando a relação BD foi sondada, contudo, ele alcançou apenas $50 \%$ (Teste 2). Então, em mais dois testes $\mathrm{DB}$, seu escore diminuiu para 57 e $60 \%$ do nível inicialmente elevado. Se o teste BD degenerou de alguma maneira o desempenho $\mathrm{DB}$, ou se a relação DB seria deteriorada de qualquer maneira, não podemos determinar. Todavia, os primeiros quatro testes do Sujeito J.O. não proporcionaram qualquer evidência convincente de formação de classes de estímulos com quatro membros. Uma série de testes foi então realizada para determinar se estes fracassos em documentar equivalência em quatro estágios eram acompanhados por ausência de uma ou mais relaçôes pré-requisitos de nível inferior.

As sondas $\mathrm{AD}$ vieram em seqüência (Teste 5), e o baixo escore de $60 \%$ indicou que as classes ACD de três membros (triângulo inferior da Figura 2) não tinham se formado. Uma vez que as sondas auditivo-visuais $\mathrm{AD}$ poderiam ajudar a reinstalar as relações $\mathrm{DB}$, as relações DB foram testadas uma vez mais; desta vez o resultado foi apenas $43 \%$ (Teste 6). A repetição da sonda $\mathrm{AD}$ (Teste 7) produziu outro escore baixo $(50 \%)$.

Uma vez que o reforçamento ocasionalmente seguia as tentativas de linha de base, mas nunca as tentativas de sonda, a deterioração do desempenho do Sujeito J.O., após seu primeiro teste, pode ter ocorrido em virtude da discriminação de tais contingências. Portanto, os testes subseqüentes omitiram o reforço após todas as tentativas, de sonda e de linha de base. Era dito à criança "Desta vez não haverá moedas - mais tarde teremos as cores com moedas". Para habituá-la com o procedimento de extinção, eram apresentados blocos de tentativas de linha de base não reforçadas, sem sondas, até que a precisão requerida fosse mantida. Então, com a precisão da linha de base sendo mantida alta durante o primeiro teste em extinção (Teste 8), as sondas DB novamente resultaram em um escore de apenas 50\%.

As próximas sondas (Teste 9), $\mathrm{BC}$ e $\mathrm{CB}$, produziram $57 \%$ e $30 \%$ de acertos, indicando que classes $\mathrm{ABC}$ com três membros (triângulo superior na Figura 2) também não tinham sido formadas. O escore $\mathrm{CB}$ baixo da criança poderia explicar a falha na emergência de relações $\mathrm{DB}$ de quatro estágios (ver TR1). Seu baixo escore BC revelou a ausência de pré-requisitos para $\mathrm{BD}$, as outras relaçôes de quatro estágios (ver TR3). Então, um escore de apenas $37 \%$ nas sondas CD 
do Teste 10 revelou que as relações $\mathrm{CD}$ não eram simétricas (as tentativas de sonda CD, na verdade, perturbaram a linha de base DC da criança - a coluna à direita na Tabela 5 não mostra outros testes em que a linha de base $\mathrm{DC}$ ficou abaixo de 90\%). A ausência da simetria DC (ver SY3) poderia ser explicada por falha na emergência das relações de quatro estágios $\mathrm{BD}$ e de três estágios $\mathrm{AD}$ (paradigmas de transitividade TR3 e TR5, respectivamente).

O baixo desempenho do Sujeito J.O. nos testes de quatro estágios $\mathrm{DB}$ e $\mathrm{BD}$ e no teste de três estágios $\mathrm{AD}$ foram consistentes com a ausência de um ou mais pré-requisitos. Na verdade, nenhum dos pré-requisitos testados emergiu. Quando foi testada a nomeação, no entanto, ele obteve o escore de $90 \%$ (Teste 1). Uma vez que a nomeação das letras poderia ter ajudado a estabelecer as relações de equivalência, foi realizado novamente o Teste DB; desta vez, ele alcançou apenas 10\% (Teste 12). Uma repetição da nomeação (Teste 13) então produziu um outro escore alto (97\%).

\section{DISCUSSÃO}

Tendo aprendido três discriminações condicionais, AB, AC, e DC (setas contínuas na Figura 2), seis das oito crianças mostraramse competentes em seis novos conjuntos de discriminaçôes condicionais que não tinham sido explicitamente ensinadas: $\mathrm{DB}, \mathrm{BD}, \mathrm{AD}, \mathrm{BC}$, $\mathrm{CB}$ e $\mathrm{CD}$ (setas tracejadas na Figura 2). Os desempenhos $\mathrm{BD}$ e DB demonstraram a emergência de três classes de estímulos com quatro membros, e as seis crianças demonstraram as propriedades necessárias de simetria e transitividade de nível mais baixo, nas relaçôes entre os membros da classe. Sem tal consistência nos pré-requisitos, a formulação de classe de estímulos necessitaria de uma grande modificação para continuar útil. Quando solicitadas a dizer o que as letras eram, as crianças as denominavam de "lambda", "xi” e "gama", de acordo com os membros da classe estabelecidos pelo procedimento. Cada relação "se ... então" era também uma relação de equivalência; os procedimentos de discriminação condicional geraram desempenhos de emparelhamento com o modelo.

A eficiência do paradigma de equivalência de quatro estágios em gerar novos desempenhos proporciona uma praticidade considerável: os vários processos de teste da equivalência produzem um notável subproduto do ensino. Após serem explicitamente ensinadas às crianças nove relações diferentes entre modelo e comparações (três representadas por cada seta contínua na Figura 2), emergiram 18 novas relações entre estímulos (três representadas por cada seta tracejada na Figura 2), e nove novas relações de nomeação oral. A razão entre desempenhos emergentes e diretamente ensinados foi de 27/9.

A eficiência do treino aumentou com o aumento do tamanho da classe de estímulos. Por exemplo, o paradigma de três estágios denominado por $\mathrm{ABC}$ na Figura 2 representa seis relaçôes entre estímulos diretamente estabelecidas, três representadas por $\mathrm{AB}$ e três por AC. Mais seis relações entre estímulos (três em BC e três em CB) e seis relaçôes de nomeação oral (B - nomeação e C - nomeação) emergiram a partir deste treino; os desempenhos emergentes excederam aqueles diretamente ensinados por um fator de dois. Assim, a construção do paradigma de quatro estágios ao ensinar as crianças a emparelhar três modelos do Conjunto D com comparaçôes do Conjunto C adicionou aos seus repertórios mais 12 relaçōes entre estímulos (três para cada uma: AD, CD, 
$\mathrm{DB}$, e $\mathrm{BD}$ ) e três relações adicionais de nomeação oral (D- nomeação); agora três desempenhos diretamente ensinados geraram 15 desempenhos emergentes, um fator de cinco. Este aumento de 2-5 vezes na eficiência do treino com o acréscimo de um único membro em cada classe de estímulos sugere a natureza potencialmente explosiva do processo.

Os desempenhos aqui envolvidos não são, em princípio, triviais. Emparelhamento entre estímulos auditivos e estímulos visuais $(\mathrm{AB}, \mathrm{AC}$, e $\mathrm{AD}$ ) pode representar a compreensão auditiva simples - compreender palavras faladas que se referem ao texto; emparelhamento entre estímulos visuais (BD, DB, $\mathrm{BC}, \mathrm{CB}, \mathrm{CD}$, e $\mathrm{DC})$ podem constituir a leitura com compreensão simples - compreensão do texto que se refere a outros objetos; a nomeação de estímulos textuais em voz alta pode ser a leitura oral simples. Muitos textos destinados a avaliar características da leitura incluem tarefas similares. Contudo, semelhanças formais entre a discriminação condicional e a leitura não demonstram a relevância de uma para a outra. O estabelecimento de classes de estímulos sim, demonstra esta relevância. Apontar para uma figura em resposta a uma palavra impressa denota a leitura com compreensão somente se a palavra e a figura estão relacionadas por equivalência e não meramente por condicionalidade. Classes de estímulos formadas por uma rede de relações de equivalência estabelece a base para o significado referencial. $\mathrm{O}$ paradigma de equivalência proporciona exatamente o teste que é necessário para determinar se ou não uma discriminação condicional particular envolve relaçōes semânticas.

Análises lingüísticas desafiam a análise comportamental funcional a explicar comportamentos novos sem história aparente de reforçamento (e.g., Comsky, 1965; Fodor, Bever,
\& Garret, 1974). O paradigma de equivalência dá um pequeno passo nessa direção pela especificação de procedimentos para gerar novos e aparentemente não reforçados emparelhamentos com o modelo e nomeação oral. Ao revelar uma classe cujos membros são relacionados por equivalência, o paradigma também evidencia a origem do reforçamento para o comportamento novo. Por definição, a existência de uma classe de estímulos equivalentes admite que qualquer variável que afete um membro de uma classe afete todos os outros membros. Mesmo quando os estímulos não compartilham semelhanças físicas, sua inclusão na classe estabelece um caminho para estender a influência do reforçamento e de outras variáveis. $\mathrm{O}$ reforçamento direto das relações $\mathrm{AB}, \mathrm{AC}$, e $\mathrm{DC}$ (Figura 2) também se estende a todos as outras possíveis relações dentro de cada classe de quatro membros. Portanto, não é correto considerar que os novos desempenhos de pareamento e nomeação emergiram sem uma história de reforçamento.

A habilidade das crianças para nomear as letras dos Conjuntos B e C confirmam experimentos anteriores que utilizaram outros tipos de estímulos (Sidman, 1971; Sidman \& Cresson, 1973; Sidman, Cresson, \& WillsonMorris, 1974). A nomeação consistente das letras do Conjunto D foi de especial interesse uma vez que as crianças nunca foram explicitamente ensinadas a selecionar aquelas letras condicionalmente aos modelos dos nomes ditados. Dois sujeitos (E.M. e I.C., Tabela 3) fizeram o teste de nomeação antes de ser testada a habilidade para emparelhar os estímulos do Conjunto $\mathrm{D}$ com os nomes ditados. A produção dos nomes do Conjunto D que eram consistentes com as classes, revelados nos testes de emparelhamento com o modelo, indica a possibilidade de que a nomeação pode ter sido necessária 
para mediar a emergência das relações condicionais. Um estudo anterior, no qual algumas relações condicionais novas emergiram antes dos sujeitos serem capazes de nomear os estímulos, sugeriu que a equivalência de estímulos era independente da nomeação (Sidman, Cresson, Willson-Morris, 1974). Aqui, o Sujeito E.W. disse todos os nomes dos estímulos que eram consistentes com os membros de sua classe, mas suas hesitações e expressões de dúvida (Tabela 4) indicaram fortemente que, embora ele fosse capaz de nomear as letras do Conjunto D, ele nunca tinha feito isto até o teste de nomeação. As novas discriminações condicionais envolvendo os estímulos do Conjunto D emergiram mesmo antes dele ter utilizado os nomes para aquelas letras.

O Sujeito E.W. foi o único dos oito que apresentou este resultado, mas a demonstração de que as classes de estímulos poderiam se formar na ausência da nomeação não pode ser rejeitada. Embora a nomeação, quando ocorre, possa de fato facilitar as relações de equivalência (Goldiamond, 1962), as respostas do Sujeito E.W. questionam fortemente a necessidade de tal função. Considerando que a nomeação não é necessária para a formação da classe, a probabilidade e a natureza de uma função facilitadora permanecem como questôes para estudo experimental.

A transcrição da nomeação na Tabela 4 indicou que as classes de estímulos poderiam emergir a partir de relações de equivalência antes mesmo do sujeito ter utilizado um nome consistente para cada membro da classe; nomeação não foi necessária. Os testes de nomeação do Sujeito J.O. (Tabela 5) mostraram que a nomeação consistente não era suficiente para estabelecer classes de estímulos a partir de relações de equivalência. Ele utilizou "lambda", "xi", e "gama” para as letras dos Conjuntos B, $\mathrm{C}$, e D de acordo com as muitas classes de quatro membros que não foram demonstradas nos testes de equivalência. Ele nomeou as letras do Conjunto D consistentemente, apesar de sua inabilidade de emparelhar aquelas letras com os seus nomes ditados.

Uma resposta que é comum a vários estímulos pode definir uma classe, mas não pode estabelecer relaçóes de equivalência entre os membros da classe. A dicotomia entre as classes definidas por nomeação e as classes definidas por equivalência não é surpresa; a relação "é o nome de", não possui as propriedades definidoras de uma relação de equivalência (Tabela 1).

Poderia ser tentador considerar a nomeação como um teste indireto de simetria das relações auditivo-visual, $\mathrm{AB}, \mathrm{AC}$, e AD. Em vez de apresentar nomes ditados como comparações, os testes de nomeação oral permitiam que as crianças produzissem os nomes em resposta às letras impressas. Parece razoável presumir que as crianças que podiam nomear as letras em voz alta poderiam também ser capazes de selecionar aqueles nomes quando eram pronunciados por outra pessoa. Entretanto, o Sujeito J.O. provou que esta pressuposição razoável estava incorreta. Sua produção precisa dos nomes das letras do Conjunto D, após mostrar-se incapaz de emparelhar aquelas letras com os seus nomes ditados, demonstrou que a nomeação emergente não constituiu um teste da simetria auditivo-visual. Novamente, uma relação possível entre nomeação e equivalência mostrou-se ilusória.

Existem semelhanças formais entre as consideraçôes da origem da equivalência de estímulos a partir dos procedimentos de discri- 
minação condicional e de pares associados. A literatura de pares associados refere-se à simetria como "associação reversa" (e.g., Ekstrand, 1966), à transitividade como "encadeamento", e aos paradigmas de equivalência A e B (Tabela 1) como "equivalência de resposta" e "equivalência de estímulos", respectivamente (e.g., Jenkins, 1963). Uma comparação completa da formulação derivada da tradição de pares associados e da que foi aqui proposta deve esperar por um veículo mais apropriado, mas pelo menos é relevante uma distinção fundamental que pode ser mascarada por similaridades terminológicas. Os métodos de pares associados, que freqüentemente requerem que o sujeito responda diferencialmente a cada estímulo a partir da produção do seu "nome" levou a uma aceitação difundida da resposta de mediação como o mecanismo responsável pelo estabelecimento das relações de equivalência (e.g., Jenkins, 1963, 1965; Jenkins \& Palermo, 1964). Apesar de ser claro que as respostas diferenciais possam mediar a emergência de novas relações entre estímulos, o uso bem sucedido das discriminações condicionais em gerar equivalências levanta dúvidas consideráveis sobre a necessidade de postular a existência de respostas de mediação. Discriminações condicionais não exigem respostas diferenciais a estímulos individuais; a única resposta pública necessária é apontar, ou tocar, que é a mesma para todos os estímulos modelo e de comparação. Algumas vezes é dito que o sujeito responde diferencialmente a cada modelo ao escolher uma determinada comparação, mas esta resposta de "escolha" pode ser definida somente com referência a um estímulo (Sidman, 1978). Portanto, a discriminação condicional envolve relações entre estímulos. Não é possível evitar esta conclusão, como alguns tentaram, reservando o termo estímulo, para estímulo modelo e empregando o termo resposta, para estímulos de comparação. Assim, em acréscimo à evidência citada acima, que mostra que a nomeação não é necessária nem suficiente para gerar equivalência de estímulos, a lógica do procedimento de discriminação condicional sugere também que não é necessário postular nenhum tipo de resposta de mediação.

\section{REFERÊNCIAS}

Chomsky, N. (1965). Aspects of the theory of syntax. Cam-bridge: The MIT Press.

Ekstrand, B. R. (1966). Backward associations. Psychological Bulletin, 65, 50-64.

Fletcher, F. G., Stoddard, L. T., \& Sidman, M. (1971). A system for unlimited repetitive presentation of auditory stimuli. Journal of Experimental Child Psychology, 11, 165-169.

Fodor, J. A., Bever, T. G., \& Garrett, M. F. (1974). The psychology oflanguage. New York: McGraw-Hill.

Goldiamond, I. (1962). Perception. In A. J. Bachrach (Ed.), Experimental foundations of clinical psychology. New York: Basic Books.

Jenkins, J. J.(1963). Mediated associations: Paradigms and situations. In C. N. Cofer, \& B. S. Musgrave (Eds.), Verbal behavior and learning: Problems and pro-cesses. New York: McGraw-Hill.

Jenkins, J. J. (1965). Mediation theory and grammatical behavior. In S. Rosenberg (Ed.), Directions in psycholinguistics. New York: Macmillan.

Jenkins, J. J., \& Palermo. D. S. (1964). Mediation processes and the acquisition of linguistic structure. In U. Bellugi \& R. Brown (Eds.), The Acquisition of language. Monographs of the Society for Research in Child Development, 29(Serial No. 92).

Lazar, R. (1977). Extending sequence-class membership with matching to sample. Journal of the Experimen- 
tal Analysis of Behavior, 27, 381-392.

Sidman, M. (1971). Reading and auditory-visual equivalents. Journal of Speech and Hearing Research, 14, 5-13.

Sidman, M. (1978). Remarks. Behaviorism, 6, 265-268.

Sidman, M., \& Cresson, O., Jr. (1973). Reading and cross-modal transfer of stimulus equivalences in severe retardation. American Journal of Mental Deficiency, 77, 515-523.

Sidman, M., Cresson, O., J., \& Willson-Morris, M. (1974). Acquisition of matching to sample via mediated transfer. Journal of the Experimental Analysis of Behavior, 22, 261-273.
Sidman, M., Rauzin, R.., Lazar. R.. Cunningham, S., Tailby, W., \& Carrigan, P. (1982). A search for symmetry in the conditional discriminations of rhesus monkeys, baboons, and children. Journal of the Experimental Analysis of Behavior, 37, 23-44.

Spradlin, J. E., Cotter. V. W., \& Baxley, N. (1973). Establishing a conditional discrimination without direct training: A study of transfer with retarded adolescents. American Journal of Mental Deficiency, 77, 556-566.

Recebido em 17 de Abril de 1981 Aceito em 6 de Agosto de 1981 


\section{PROGRAMAS DE PÓS-GRADUAÇÃO STRICTO SENSU EM ANÁLISE DO \\ COMPORTAMENTO NO BRASIL \\ BRAZILIAN GRADUATE PROGRAMS IN BEHAVIOR ANALYSIS}

\section{PROGRAMA DE PÓS-GRADUAÇÃO EM EDUCAÇÃO ESPECIAL}

Concentração em Educação do Indivíduo Especial

\section{UNIVERSIDADE FEDERAL DE SÃO CARLOS}

Coordenadora: MARIA AMELIA ALMEIDA

Cursos: MESTRADO EDOUTORADO

Docentes da Linha de Pesquisa Aprendizagem e Cognição

(com orientação em Análise do Comportamento):

Antonio Celso de Noronha Goyos

Deisy das Graças de Souza

Júlio César C. de Rose

Maria de Jesus Dutra dos Reis

Maria Stella Coutinho de Alcântara Gil

Página da internet para obter informações adicionais e e-mail para contato: http:// www.cech.ufscar.br/ppgees/index.htm 
PPROGRAMAS DE PÓS-GRADUAÇÃO STRICTO SENSU EM ANÁLISE DO

COMPORTAMENTO NO BRASIL

BRAZILIAN GRADUATE PROGRAMS IN BEHAVIOR ANALYSIS

PROGRAMA DE PÓS GRADUAÇÃO EM PSICOLOGIA EXPERIMENTAL

Áreas de concentração:

ANÁLISE EXPERIMENTAL DE CONTINGÊNCIAS COMPORTAMENTAIS

COMPORTAMENTO ANIMAL E ETOLOGIA HUMANA

PROCESSOS COGNITIVOS, AFETIVOS E SOCIAIS NO SER HUMANO

PROBLEMAS TEÓRICOS E METODOLÓGICOS DA PESQUISA PSICOLÓGICA

Departamento de Psicologia Experimental

Universidade de São Paulo

Coordenadora: Maria Martha Costa Hübner

Cursos: MESTRADO E DOUTORADO

Docentes da área de concentração em Análise do Comportamento

Gerson Aparecido Yukio Tomanari

Maria Helena Hunziker

Maria Martha Costa Hübner

Maria Teresa Araújo Silva

Paula Debert

Página da internet para obter informações adicionais e e-mail para contato www.ip.usp.br 